\title{
Estimation of Contact Resistivity in Lightning Protection Equipotential Bonding Joints of Wind Turbine Blades
}

\author{
Antonio A.M. Laudani, Evangelos C. Senis, Paul L. Lewin, Igor O. Golosnoy, Jochen Kremer, \\ Hendrik Klein, Ole T. Thomsen
}

\begin{abstract}
Modern lightning protection systems for wind turbine blades with conducting structural elements, e.g., carbon fibre reinforced polymer (CFRP) spar caps, contain equipotential bonding joints to prevent sparking during strikes. Significant current levels are experienced through the joints and the characterization of the electrical contact at the bonding regions is essential for reliable protection. Therefore, this article aims to characterize the contact resistivity of several equipotential bonding joints. The proposed methodology first measures the total resistance of the samples, and then the bulk resistance of the conductive elements is computed using the finite-element method. The latter is required to predict the spreading effects in CFRP components due to the strong anisotropic nature of such materials. After that, the contact resistance is calculated by subtracting the predicted bulk resistances from the measured total resistances. The developed procedure was applied to three typical equipotential bonding materials: expanded copper foil (ECF), biaxial (BIAX) CFRP and unidirectional (UD) CFRP. Both ECF and BIAX CFRP showed superior contact quality than UD CFRP, with one to two orders of magnitude smaller contact resistivity.
\end{abstract}

Index Terms - Contact resistivity, equipotential bonding (EB), finite-element method (FEM), lightning protection, wind turbine blade.

\section{INTRODUCTION}

$\mathrm{T}$ HE ever-increasing demand for wind turbines with higher rated power outputs led to the need for larger rotor diameters, which can reach up to $220 \mathrm{~m}$ [1]. To meet the desired rated power requirements and to maintain a low weight, wind turbine manufacturers implemented carbon fibre reinforced polymer (CFRP) materials into the rotor blade load-carrying laminates, i.e., the spar caps [2]-[5]. However, several studies on wind turbine systems have shown that CFRP materials make modern rotor blades highly susceptible to downward lightning strikes, as well as to triggering upward lightning [6]-[10]. Consequently, it is required to equip them with a lightning protection system (LPS) capable of preventing damage due to lightning direct attachment. LPSs are composed of metal

This paper was submitted for review on 03/09/2020.

This study was funded by the EU Horizon 2020 Marie Sklodowska-Curie Actions - Innovative Training Networks (ITN), grant agreement No 642771 (SPARCARB project), and by Nordex Energy GmbH and the University of Southampton, grant agreement 0179210.

A.A.M. Laudani (a.a.m.laudani@soton.ac.uk), E.C. Senis (e.senis@soton.ac.uk), P.L. Lewin (pll@ecs.soton.ac.uk) and I.O. Golosnoy (i.golosnoy@soton.ac.uk) are with The Tony Davies High Voltage Laboratory, receptors placed over the blade surface and metal down conductors (DCs) located in the cavity of the blade. The former is aimed to intercept the lightning leaders, whereas the latter is intended to conduct the lightning current from the attachment point to the earthing system [11], [12]. The receptors have to be designed according to the procedures specified in the IEC standard [12] to transfer most of the lightning energy to the DC and avoid damage [7], [9].

The incorporation of CFRP materials introduces additional challenges for the protection of the blade against lightning strikes. For instance, internal arcs due to high potential differences develop between the DC and the CFRP structure, which would cause severe structural damage to the spar [13], [14]. To prevent this, the two conductors are electrically connected such that to split the lightning current between them and obtain the same electric potential. However, thermal damage is usually observed at the bonding areas. In fact, such connections are obtained by laying layers of equipotential bonding (EB) material around the DC and the CFRP spar and fixing them by epoxy resin during the infusion process of the blade [15]. Because of the presence of resin-rich areas, high values of contact resistance are often found at the joint interfaces, which leads to elevated temperatures and evaporation of the epoxy around the bonding points. The produced high-pressure gasses can in turn ignite sparking events causing delamination within the composite joint. The prevention of sparking phenomena dictates the requirement on low contact resistivity at the joint interfaces [16]-[23].

In recent years, tools such as the finite-element method (FEM) are increasingly being used [24]-[28] to reduce the lightning testing costs, which can reach up to $€ 100,000$ including material and manufacturing of testing samples [27]. One of the advantages of numerical simulations for lightning strike analysis is the capability of computing spatial current density distributions in the rotor blade cross section, which are not easily measurable during high-current tests. In order to

School of Electronics and Computer Science, University of Southampton, University Road, Southampton, SO17 1BJ, United Kingdom.

J. Kremer (jkremer@nordex-online.com) and H. Klein (hklein2@nordexonline.com) are with Nordex Energy GmbH, Langenhorner Chaussee 600, Hamburg, 22419, Germany.

O.T. Thomsen (o.thomsen@bristol.ac.uk) is with the Bristol Composite Institute (ACCIS), Department of Aerospace and Engineering, University of Bristol, University Walk, Bristol, BS8 1TR, United Kingdom. 
achieve accurate current density and temperature predictions and design reliable lightning protection solutions, it is essential to model the electrical contact at the EB regions [11], [12], [29]. However, no experimental method has so far been proposed to characterize the electrical contact for assemblies composed of metallic and CFRP parts [22], [23], [29]. Therefore, the objective of this article is to develop a procedure capable of quantifying the electrical contact resistivity of different EB joints used in wind turbine blades. First, the total resistance of the assessed samples is measured using the two-probe method. After that, the complex geometrical arrangement of such assemblies (which present external insulating glass composite layers) requires the use of the FEM to predict: the bulk resistances of the conducting parts (i.e., DC, equipotential layers and spar); and the spreading effects in CFRP components caused by the strong anisotropy of such materials. Finally, the contact resistance is estimated by subtracting the values of bulk and spreading resistances predicted by the FEM from the measured total resistances. Since equipotential joints present two contact regions (i.e., the contact between the DC and the connections and the contact between the connections and the spar), the whole assembly is split into two subsystems to assess the resistivity at the two interfaces individually.

The proposed technique is very generic, and its use is not limited to EB only. For instance, it could be employed to characterize the electrical contact of aerospace fasteners, such as riveted and bolted joints.

\section{Materials AND Methods}

\section{A. Materials}

As a matrix, a two-component epoxy system was employed during the infusion process, which was supplied by Hexion. It comprised of Hexion RIMR035c epoxy resin and Hexion RIMH037 curing agent. For the CFRP spar, a unidirectional (UD) non-crimp carbon fabric with an aerial density of 870 $\mathrm{g} / \mathrm{m}^{2}$, supplied by Saertex, was utilised. Three different materials were employed as EB between the CFRP spar and the copper LPS DC: UD noncrimp carbon fabric $\left(600 \mathrm{~g} / \mathrm{m}^{2}\right)$; biaxial (BIAX) noncrimp carbon fabric $\left(218 \mathrm{~g} / \mathrm{m}^{2}\right)$; and expanded copper foil (ECF) 4Cu14-125. Both UD and BIAX noncrimp carbon fabrics were supplied by Saertex, whereas the ECF was supplied by Dexmet Co., USA [30]. The latter consisted of copper Alloy C11000 [31] and was characterized by a nominal thickness of $0.101 \mathrm{~mm}$, strand width of $0.356 \mathrm{~mm}$, long way of the diamond and short way of the diamond approximately equal to $3.175 \mathrm{~mm}$ and $1.397 \mathrm{~mm}$, respectively. Finally, the samples were encapsulated within a BIAX noncrimp glass fabric with an aerial density of $1,010 \mathrm{~g} / \mathrm{m}^{2}$, which was supplied by Saertex.

\section{B. Sample Geometry and Manufacturing}

Fig. 1 depicts a typical arrangement of the wind turbine blade internal components [27]. The system is composed of a DC, a spar made of UD CFRP and two EB layers connecting the top and bottom surfaces of the DC and spar. Two main contact regions are identified: the contact region between the down conductor and the equipotential bonding layers (C_DC-EB); and the contact region between the equipotential bonding layers and the spar (C_EB-SPAR). For a more accurate estimation of the electrical contact behavior, it was decided to separate the contribution of the two contact regions to the total interface resistance, i.e., two distinct values of contact resistance were estimated for the two contact regions. This was achieved by designing two different types of specimen: the DC-EB specimen [see Fig. 2(a)], which is composed of a DC and two EB layers and allowed to determine the contact resistance between the DC and the connections; and the DC-EB-SPAR_1 specimen [see Fig. 2(b)], which consists of a DC, two EB layers, and a constant thickness CFRP spar and enabled to characterize the contact resistance between the connections and the spar. Typical spar geometries of rotor blades present chamfer profiles for mechanical purposes [27]. From a lightning protection point of view, it is beneficial to place equipotential connections on these surfaces since the current can directly be injected into each spar layer and thus through the entire spar cross section [27]. Therefore, three other samples
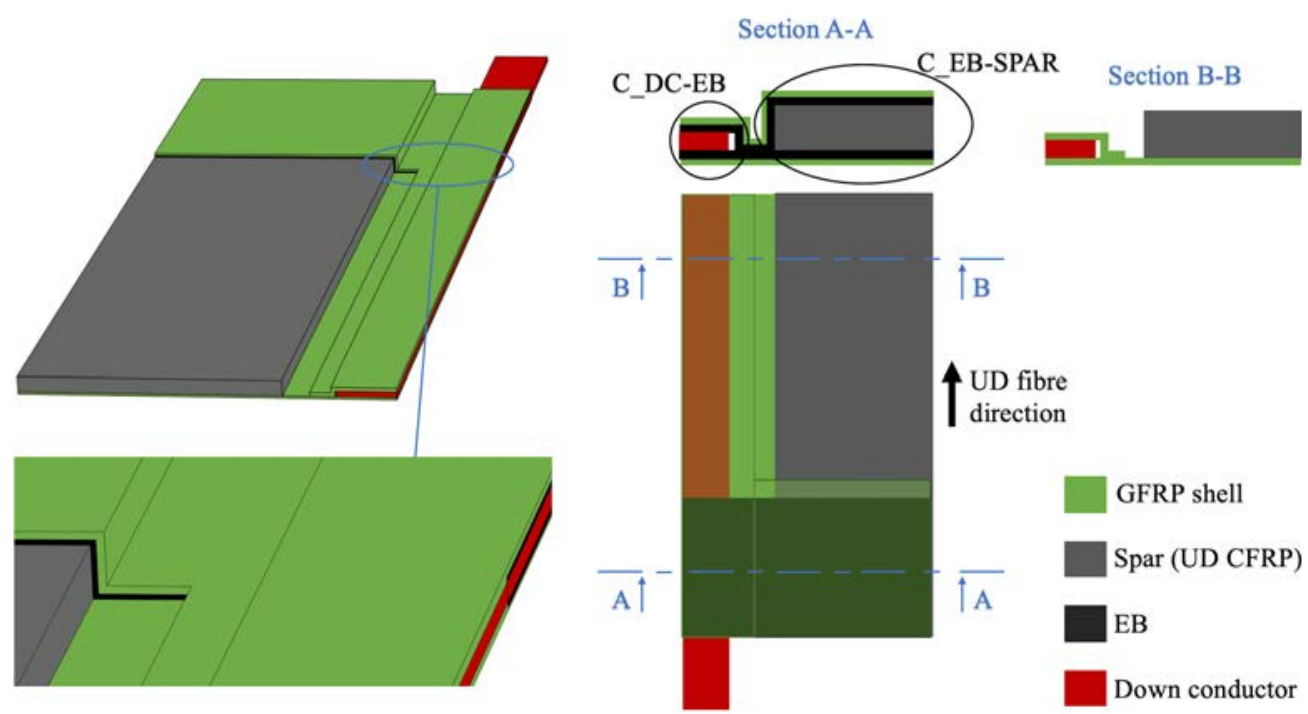

Fig. 1. Typical arrangement of wind turbine blade internal components. 


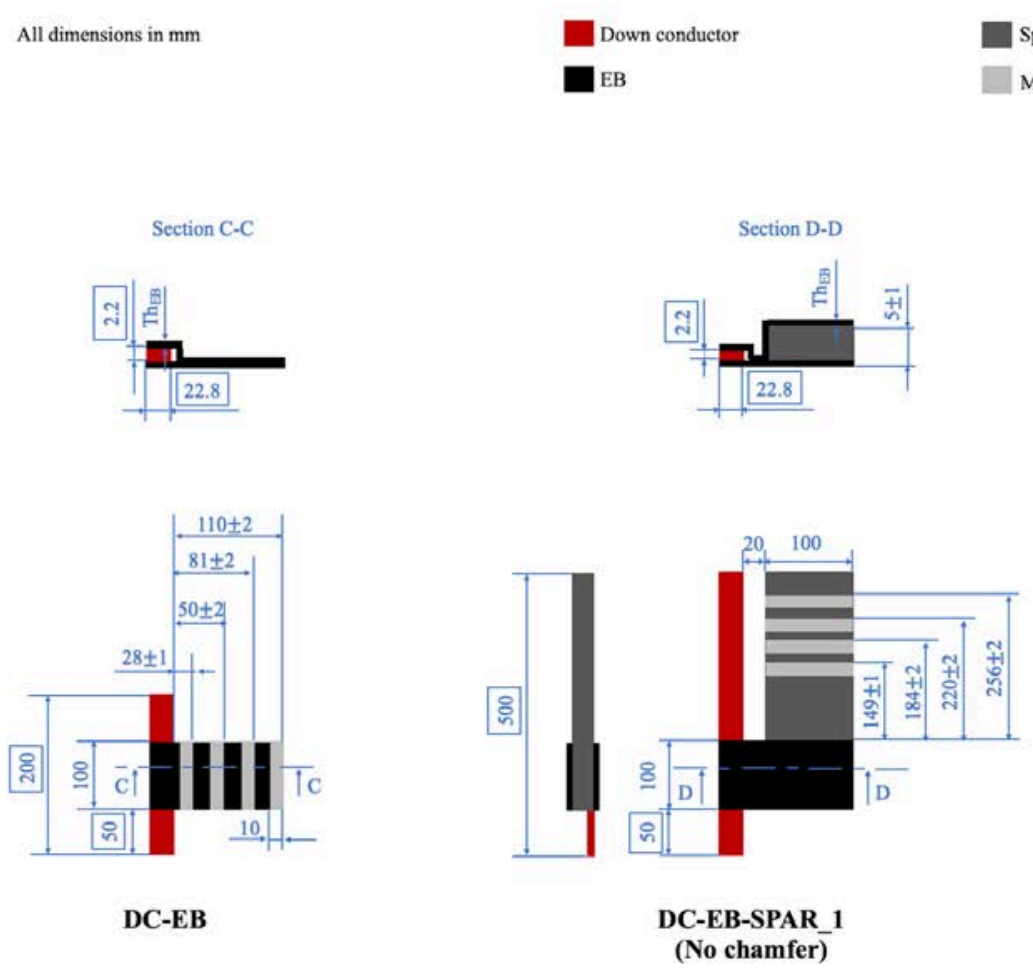

(a) (b)
Measuring electrodes

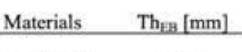

UD CFRP $\quad 0.717$

BIAX CFRP $\quad 0.214$

ECF

0.35

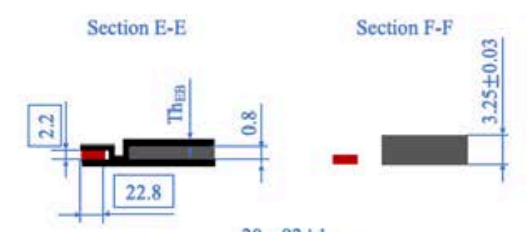

1

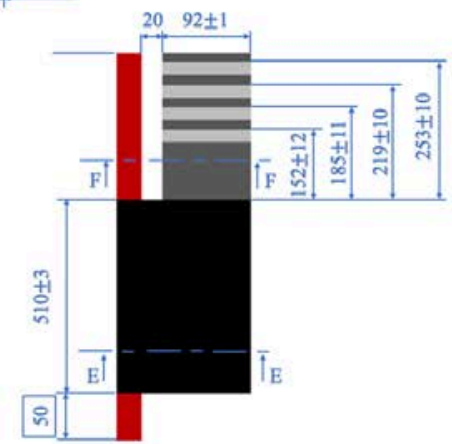

DC-EB-SPAR 2

$\gamma=0.274^{\circ} \pm 0.003^{\circ}($ chamfer $\mathrm{c}$ in [27])

(c)

Fig. 2. Assessed samples: (a) DC-EB, (b) DC-EB-SPAR_1 (no chamfer) and (c) DC-EB-SPAR_2 (chamfer c).

were designed to investigate the effects of the chamfer angle $\gamma$ $\left[{ }^{\circ}\right]$ on the contact resistance: DC-EB-SPAR_2 [see Fig. 2(c)], DC-EB-SPAR_3, and DC-EB-SPAR_4 samples. Both DC-EBSPAR 3 and DC-EB-SPAR 4 samples are not shown in Fig. 2 as they are identical to DC-EB-SPAR_2 but with different dimensions and chamfer angles.

To achieve conditions similar to ones encountered in the production of wind turbine blades, all samples were manufactured by means of the vacuum-assisted resin transfer molding process [2]-[5]. The UD CFRP spar sample was obtained by stacking layers of dry carbon fabric (five layers for the DC-EB-SPAR_1 samples, four layers for both the DC-EBSPAR_2 and DC-EB-SPAR_3 samples, and three layers for the DC-EB-SPAR 4 samples) into a flat mold, whereas a copper braid (LPS DC) with a cross section of $50 \mathrm{~mm}^{2}$ [12] was positioned in parallel to the laminate. EB layers were then placed in the desired positions to connect the DC to the spar, as shown in Fig. 1. Finally, to be consistent with the actual structure of the rotor blade, the whole system (i.e., CFRP spar/copper braid/EB) was encapsulated into glass fibre reinforced polymer (GFRP) layers and infused at the same time under vacuum. The samples were cured for $6 \mathrm{~h}$ at $75{ }^{\circ} \mathrm{C}$ following the instructions of the resin supplier. The fibre volume fraction of the laminates was approximately $53 \%$. Four specimens per each configuration were manufactured and assessed in order to account for any variation in the contact quality caused by the manufacturing process.

\section{Experimental Technique}

Before conducting the experiment, it was essential to prepare the sample surfaces that were intended to act as electrodes.
First, the top surface of the sample was sanded down in order to remove the excess epoxy resin and expose the carbon fibres [32]-[34]. The sanding process was performed by means of 180 grit Silicon Carbide abrasive paper until carbon fibres were visible, followed by 300 and 600 grit to finish the surface. Second, measuring electrodes were obtained on the sanded areas by means of copper tapes. To reduce the electrode contact resistance, the copper tapes were attached to the sample surface using conductive silver paint with a bulk conductivity of $1 \times 10^{5}$ $\mathrm{S} / \mathrm{m}$, which was supplied by RS Components. The silver paste was left to cure for $30 \mathrm{~min}$ at ambient temperature, as specified by the supplier [35].

The maximum direct current injected in both DC-EB and DC-EB-SPAR samples was limited to $50 \mathrm{~mA}$ to mitigate Joule heating effects and avoid any damage. In addition, some studies have shown that both the bulk electrical resistivity [36]-[38] and the electrical contact resistivity [39]-[41] of CFRPs decrease with increasing temperatures. Thus, by conducting the experiment at ambient temperature, the electrical contact was characterized in the worst case scenario, i.e., the case with the highest electrical contact resistivity. Under such conditions, the total resistance of both DC-EB and DC-EB-SPAR samples was measured through the AIM TTi BS-407 low resistance ohmmeter using the two-probe method depicted in Fig. 3(a). This method was chosen since it includes the sought values of contact resistance into the total measurements. A pressure equal to $20 \mathrm{MPa}$ was applied through a hydraulic press on the metal electrodes during the measurements in order to mitigate the effects of the surface roughness and improve the ohmic contact [42]. In addition, an aluminium block insulated from the current path was placed between the sample and the press cylinder to 
spread the applied force over the entire electrode surface. All measurements were conducted at a temperature of $25^{\circ} \mathrm{C}$ and with a relative humidity of $55 \%$.

The experiment was first performed on the DC-EB sample depicted in Fig. 3(a), which was designed to characterize the contact resistance between the DC and the EB layers. This system is equivalent to the electric circuit shown in Fig. 3(a) when considering the contact resistance between the conductors and the contact resistance of the measuring electrodes. The developed procedure required to measure the total resistance at different lengths of the specimen, which was assumed linearly distributed since the resistance of the EB strip is directly proportional to the strip length

$$
\begin{aligned}
R_{D C-E B_{-} \text {Tot }}\left(L_{S}\right) & =R_{D C}+R_{C_{-} D C-E B}+\frac{1}{\frac{1}{R_{E B 1}}+\frac{1}{R_{E B 2}}}+ \\
& +R_{E B 3}\left(L_{S}\right)+R_{C_{-} \text {Electrodes }}
\end{aligned}
$$

where $R_{D C-E B_{-} T o t}[\Omega]$ is the total resistance of the DC-EB sample, $L s[\mathrm{~m}]$ is the sample length, $R_{D C}[\Omega]$ is the resistance of the $\mathrm{DC}, R_{C_{-} D C-E B}[\Omega]$ is the contact resistance between the $\mathrm{DC}$ and the equipotential connections (the value to be determined), $R_{E B I}[\Omega]$ is the resistance of the EB layer at the top of the DC, $R_{E B 2}[\Omega]$ is the resistance of the EB layer at the bottom of the $\mathrm{DC}, R_{E B 3}[\Omega]$ is the resistance of the horizontal EB layer, and $R_{C_{-} \text {Electrodes }}[\Omega]$ is the contact resistance of the measuring electrodes.

By moving the measuring electrode over the surface of the EB layer we were varying the resistance $R_{E B}$, which was zero when $L s=0$ [see Fig. 3(b)]. This point corresponded to the yaxis intercept, which was determined after interpolating the measured resistance values

$I n t_{D C-E B_{-} E x p}=R_{D C}+R_{C_{-} D C-E B}+\frac{1}{\frac{1}{R_{E B 1}}+\frac{1}{R_{E B 2}}}+R_{C_{-} \text {Electrodes }}$

where $\operatorname{Int}_{D C-E B_{-} E x p}[\Omega]$ is the experimental y-axis intercept of the DC-EB sample.
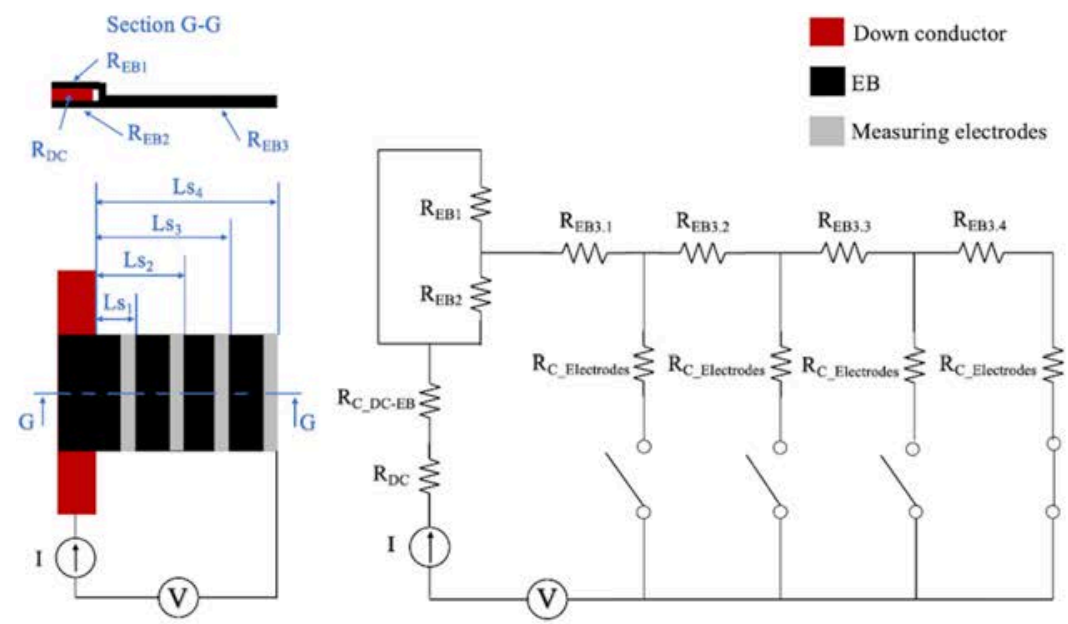

(a)

Fig. 3. Characterization of $\mathrm{R}_{\mathrm{C} \_\mathrm{DC}-\mathrm{EB}}$ : (a) electric circuit arrangement and (b) interpolation procedure.
As shown in (2), the expression of the y-axis intercept included the contact resistance of the measuring electrodes, i.e., $R_{C_{-} \text {Electrodes. This }}$ resistance needed to be quantified and subtracted from the $y$-axis intercept value to avoid an overestimation of the sought contact resistance, i.e., $R_{C_{-} D C-E B}$. This was realized by measuring the total resistance of the sample when injecting the current in one measuring electrode and extracting it from the following ones [see Fig. 4(a)]. The values of total resistance measured by this circuit were equal to $R_{\text {Tot }}\left(L_{S}\right)=R_{E B 3}\left(L_{S}\right)+2 \cdot R_{C_{-} \text {Electrodes }}$

where $R_{T o t}[\Omega]$ is the total resistance of the system depicted in Fig. 4(a).

The values of measured resistance were interpolated and the intercept with the y-axis [see Fig. 4(b)] represented the contact resistance of the measuring electrodes, which was subtracted from (2)

$$
I n t_{D C-E B_{-} E x p}^{C o r r}=R_{D C}+R_{C_{-} D C-E B}+\frac{1}{\frac{1}{R_{E B 1}}+\frac{1}{R_{E B 2}}}
$$

where $I n t_{D C-E B_{E} E x p}^{C o r}[\Omega]$ is the experimental y-axis intercept of the DC-EB sample corrected from the contact resistance of the measuring electrodes.

The same procedure was repeated to characterize the total resistance of the DC-EB-SPAR samples [see Fig. 5(a)]

$$
\begin{gathered}
R_{D C-E B \text {-SPAR_Tot }}\left(L_{S}\right)=R_{D C}+R_{C_{-} D C-E B}+\frac{1}{\frac{1}{R_{E B 1}}+\frac{1}{R_{E B 2}}}+ \\
+R_{E B 3}+R_{C_{-} E B-S P A R}+\frac{1}{\frac{1}{R_{E B 4}}+\frac{1}{R_{E B 5}}+\frac{1}{R_{E B 6}}}+ \\
+R_{S P A R}\left(L_{S}\right)+R_{C_{-} \text {Electrodes }}
\end{gathered}
$$

where $R_{D C-E B-S P A R_{-} T o t}[\Omega]$ is the total resistance of the DC-EBSPAR sample, $R_{C_{-} E B-S P A R}[\Omega]$ is the contact resistance between the EB layers and the spar (the value to be determined), $R_{E B 4}$ $[\Omega]$ is the resistance of the EB layer on the side surface of the spar, $R_{E B 5}[\Omega]$ is the resistance of the EB layer at the bottom of

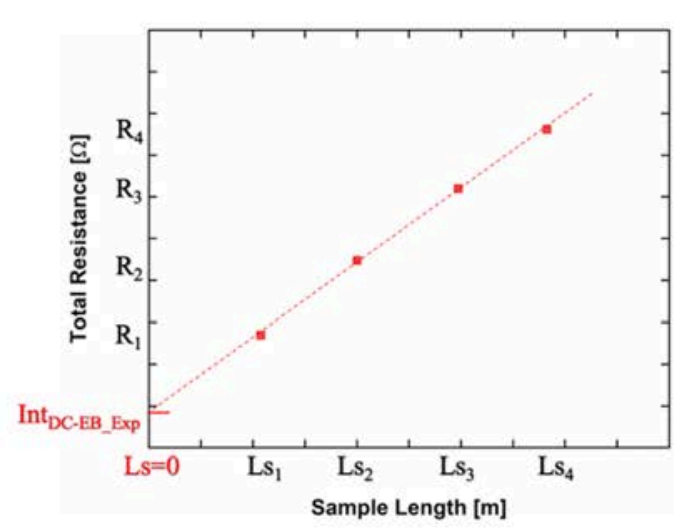

(b) 


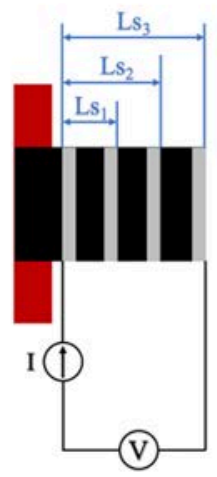

(a)

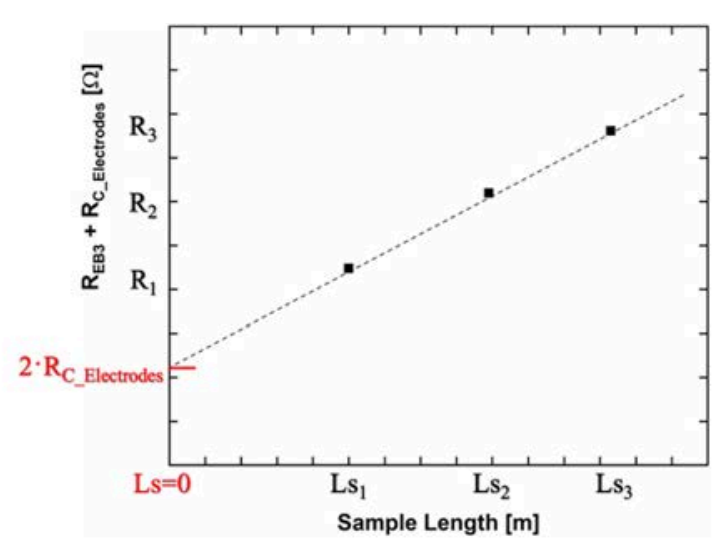

(b)

Fig. 4. Characterization of $\mathrm{R}_{\mathrm{C} \_ \text {Electrodes }}$ for the DC-EB sample: (a) electric circuit arrangement and (b) interpolation procedure.

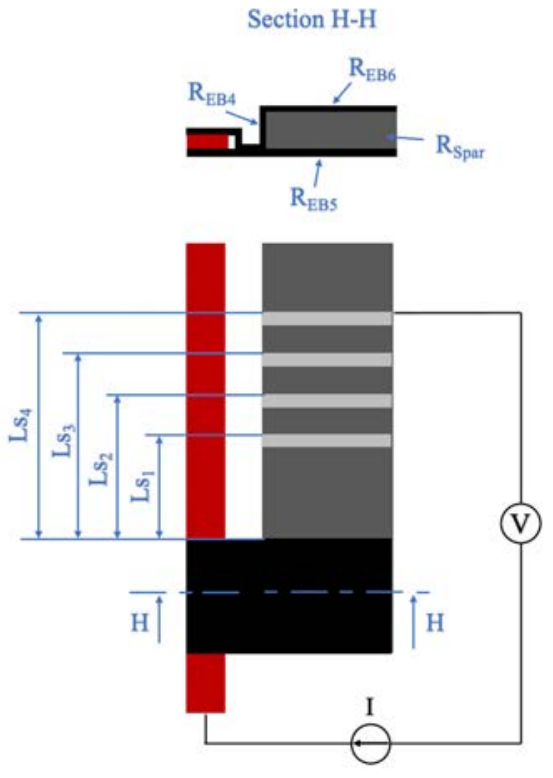

(a)

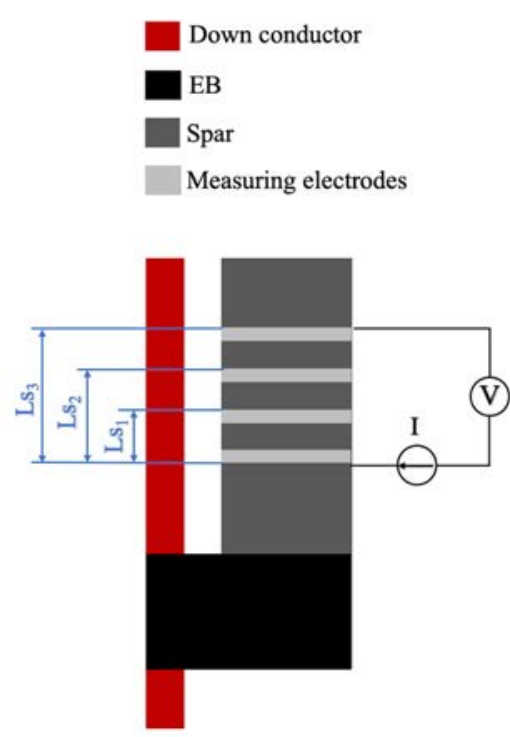

(b)

Fig. 5. Electric circuit arrangement of the DC-EB-SPAR sample for: (a) the characterization of $\mathrm{R}_{\mathrm{C}_{-} E B-S P A R}$ and (b) the characterization of $\mathrm{R}_{\mathrm{C}_{-} E l e c t r o d e s}$.

the spar, $R_{E B 6}[\Omega]$ is the resistance of the EB at the top of the spar, and $R_{S P A R}[\Omega]$ is the resistance of the spar.

The experimental $y$-axis intercept of the DC-EB-SPAR sample was

$$
\begin{gathered}
\text { Int }_{D C-E B-S P A R_{-} E x p}=R_{D C}+R_{C_{-} D C-E B}+\frac{1}{\frac{1}{R_{E B 1}}+\frac{1}{R_{E B 2}}}+ \\
+R_{E B 3}+R_{C_{-} E B-S P A R}+\frac{1}{\frac{1}{R_{E B 4}}+\frac{1}{R_{E B 5}}+\frac{1}{R_{E B 6}}}+ \\
+R_{C_{-} \text {Electrodes }}
\end{gathered}
$$

where $I_{D} t_{D C-E B-S P A R_{-}} x_{x}[\Omega]$ is the experimental y-axis intercept of the DC-EB-SPAR sample.

The contact resistance of the measuring electrodes was determined as in Fig. 5(b) and subtracted from (6)

$$
I n t_{D C-E B-S P A R_{-} E x p}^{\text {Corr }}=R_{D C}+R_{C_{-} D C-E B}+\frac{1}{\frac{1}{R_{E B 1}}+\frac{1}{R_{E B 2}}}+
$$

$$
+R_{E B 3}+R_{C_{-} E B-S P A R}+\frac{1}{\frac{1}{R_{E B 4}}+\frac{1}{R_{E B 5}}+\frac{1}{R_{E B 6}}}
$$

where $I n t_{D C-E B-S P A R_{-} E x p}^{\text {Corr }}[\Omega]$ is the experimental y-axis intercept of the DC-EB-SPAR sample corrected from the contact resistance of the measuring electrodes.

The values of interface resistance contained in (4) and (7) can be determined if the resistance of the individual conductors ( $R_{D C}, R_{E B}$, and $R_{S P A R}$ ) are somehow estimated. This was done by means of numerical simulations using the electrical conductivity of the employed materials as input parameters.

\section{NUMERICAL ANALYSIS}

In the previous section we presented the experimental procedures employed for the characterization of the contact resistance in wind turbine blade EB joints. The experimental intercepts with the y-axis given in (4) and (7) contained the information of the interface resistances to be determined $\left(R_{C_{-} D C}\right.$ $E B$ and $\left.R_{C_{-} E B-S P A R}\right)$ as well as the bulk resistances of the down 
conductor, equipotential bonding and spar $\left(R_{D C}, R_{E B}\right.$ and $\left.R_{S P A R}\right)$. The latter needed to be computed and subtracted from the yaxis intercepts in such a way as to isolate the sought contact resistances. This was not a trivial task since the system presented CFRP components, which behave as spreading resistances [42], [43]. In fact, the spreading of the current within these parts is not identical in the three principal directions because of the strong anisotropy of CFRP materials (up to four orders of magnitude difference in electrical conductivity). Spreading effects require several complex assumptions for rough analytical estimations. On the other hand, more accurate predictions of current distributions and spreading resistances can be obtained using the FEM [44]-[46] by specifying the materials' electrical conductivity as input parameters. To this end, the experiment was simulated using COMSOL Multiphysics 5.5.

\section{A. Electric Current Problem}

\section{1) Model Formulation}

Since the aim was to quantify the bulk resistances $\left(R_{D C}, R_{E B}\right.$ and $\left.R_{S P A R}\right)$ and subtract them from the experimental y-axis intercepts to determine the sought contact resistances $\left(R_{C_{-} D C-E B}\right.$ and $R_{C_{-} E B-S P A R}$, it was considered ideal contact between the conductors while solving for the electric potential assuming current conservation [47], [48]:

$\nabla \cdot(-\sigma \nabla V)=0$

where $\nabla \cdot$ is the divergence operator, $\sigma[\mathrm{S} / \mathrm{m}]$ is the electrical conductivity tensor of the conductors, $\nabla$ is the gradient operator and $V[\mathrm{~V}]$ is the electric scalar potential.

\section{2) Input Material Properties}

The electrical conductivity of the spar, EB and DC materials is listed in Table 1. The anisotropic conductivity of both UD and BIAX were experimentally measured according to the procedures described in [49]. The ECF electrical conductivity was considered anisotropic as done in past research [50], [51]. Finally, the nomenclature of conductivity axes is provided in Fig. 6.

\section{3) Geometry, Boundary Conditions and Mesh}

The geometry of the specimens under testing, i.e., DC-EB and DC-EB-SPAR, was modelled in COMSOL Multiphysics 5.5 to predict the spreading resistance. As an example, Fig. 7 shows the geometry, mesh and boundary conditions of the DCEB-SPAR_2. Electric insulation $(\mathbf{n} \cdot \boldsymbol{J}=0$, where $\mathbf{n}$ is the normal and $\boldsymbol{J}\left[\mathrm{A} / \mathrm{m}^{2}\right]$ is the current density) was assumed at all the external boundaries of the model with the exception of the current injection and ground surfaces of the DC and spar, respectively. The automatic mesh refinement option was used to minimise the errors [47], [48] and the final meshes of DCEB and DC-EB-SPAR models consisted of 37000 and 73000 hexahedral elements and boundary layers, respectively. Boundary layers were employed to capture the electric potential jump due to the contact resistance and for an accurate representation of the current distribution at the contact surfaces.

\section{B. Contact Resistance and Contact Resistivity}

When simulating the experiment for the DC-EB sample and assuming ideal contact, the FEM intercept with the y-axis was equal to (see also Fig. 8)

$$
I n t_{D C-E B_{-} F E M}=R_{D C}+\frac{1}{\frac{1}{R_{E B 1}}+\frac{1}{R_{E B 2}}}
$$

Table 1. Spar, EB and DC electrical conductivity.

\begin{tabular}{lccc}
\hline Materials & $\sigma_{11}[\mathrm{~S} / \mathrm{m}]$ & $\sigma_{22}[\mathrm{~S} / \mathrm{m}]$ & $\sigma_{33}[\mathrm{~S} / \mathrm{m}]$ \\
\hline UD CFRP (spar) & 36,380 & 17.910 & 3.950 \\
UD CFRP (equipotential bonding) & 33,874 & 26.30 & 11.62 \\
BIAX CFRP (equipotential bonding) & 20,702 & 20,702 & 8.340 \\
ECF (equipotential bonding) [30] & $2.187 \times 10^{7}$ & $6.038 \times 10^{6}$ & $1.968 \times 10^{7}$ \\
Copper (down conductor) [27] & $5.998 \times 10^{7}$ & $5.998 \times 10^{7}$ & $5.998 \times 10^{7}$
\end{tabular}

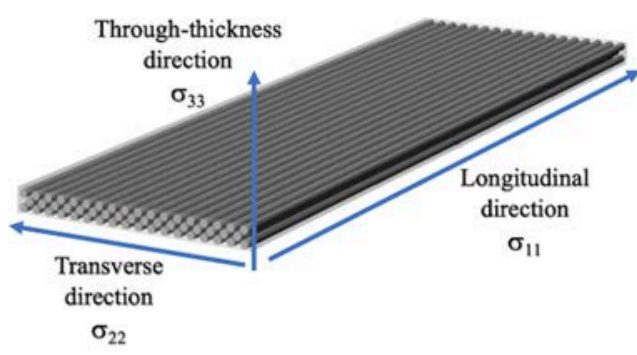

(a)

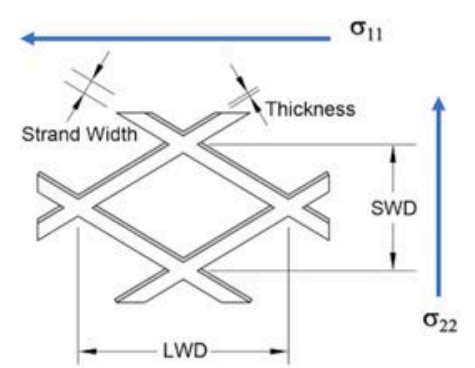

(b)

Fig. 6. Nomenclature of conductivity axes for: (a) CFRP and (b) ECF [51]. 


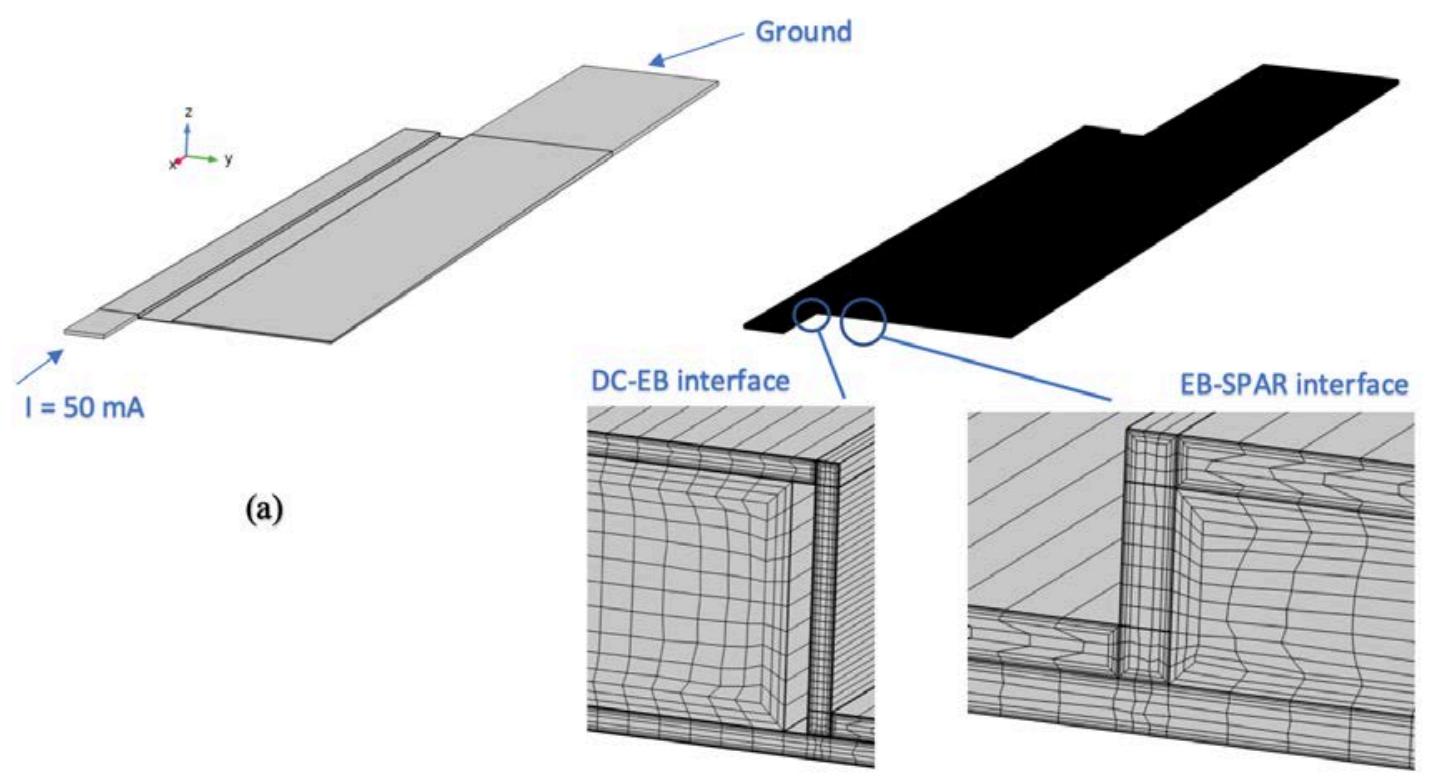

(b)

Fig. 7. FEM modeling: (a) geometry and boundary conditions and (b) mesh.

where Int $_{D C-E B_{-} F E M}[\Omega]$ is the FEM y-axis intercept of the DCEB sample.

On the other hand, the FEM y-axis intercept of the DC-EBSPAR sample when considering ideal contact was

$$
\begin{gathered}
\text { Int }_{D C-E B-S P A R_{-} F E M}=R_{D C}+\frac{1}{\frac{1}{R_{E B 1}}+\frac{1}{R_{E B 2}}}+R_{E B 3}+ \\
+\frac{1}{\frac{1}{R_{E B 4}}+\frac{1}{R_{E B 5}}+\frac{1}{R_{E B 6}}}
\end{gathered}
$$

where IntDC-EB-SPAR_FEM $[\Omega]$ is the FEM y-axis intercept of the DC-EB-SPAR sample.

By taking the difference between (4) and (9), it was possible to determine the contact resistance between the $\mathrm{DC}$ and the $\mathrm{EB}$ layers

$R_{C_{-} D C-E B}=I n t_{D C-E B_{-} E x p}^{C o r r}-\operatorname{Int}_{D C-E B_{-} F E M}$.

Similarly, by taking the difference between (7) and (10), and subtracting $R_{C_{-} D C-E B}$ found by (11), it was possible to determine the contact resistance between the EB layers and the spar $R_{C_{-} E B-S P A R}=I n t_{D C-E B-S P A R_{-} E x p}-I_{\text {Int }} t_{D C-E B-S P A R_{-} F E M}-R_{C_{-} D C-E B}$.

Finally, commercial FEM packages (COMSOL Multiphysics as well as others) model electrical contacts as homogeneous surface conditions [47], [48]. Consequently, it was required to determine the contact resistivity by multiplying the interface resistance by the contact surface [52]-[57]

$\rho_{C_{-} D C-E B}=R_{C_{-} D C-E B} \cdot A_{C_{-} D C-E B}$

and

$\rho_{\mathrm{C}_{-} \mathrm{EB}-\mathrm{SPAR}}=R_{C_{-} E B-S P A R} \cdot A_{C_{-} E B-S P A R}$

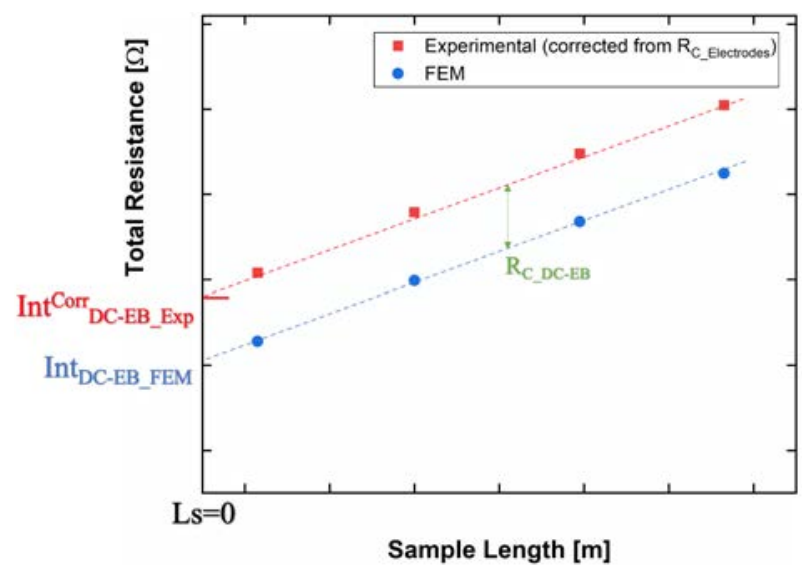

Fig. 8. Schematic of the procedure to estimate the contact resistance.

where $\rho_{C \_D C-E B}\left[\Omega \cdot \mathrm{m}^{2}\right]$ is the contact resistivity between the DC and the EB layers, $A_{C_{-} D C-E B}\left[\mathrm{~m}^{2}\right]$ is the contact surface between the DC and the EB layers, $\rho_{C_{-} E B-S P A R}\left[\Omega \cdot \mathrm{m}^{2}\right]$ is the contact resistivity between the EB layers and the spar, and $A_{C_{-} E B-S P A R}$ $\left[\mathrm{m}^{2}\right]$ is the contact surface between the EB layers and the spar.

Note that since the contact area between the DC and EB layers is the same for both DC-EB and DC-EB-SPAR_1 samples [i.e., $0.00456 \mathrm{~m}^{2}$, see Fig. 2 (a) and (b)], $R_{C_{-} D C-E B}$ was directly subtracted in (12) to isolate the term $R_{C_{-} E B-S P A R}$. However, this contact area is bigger in the chamfered samples [see Fig. 2(c)], which follows that the contact resistance $R_{C_{-} D C}$ $E B$ to be subtracted in (12) needed to be determined from the contact resistivity $\rho_{C_{-} D C-E B}$ as in the following equation:

$R_{C \_D C-E B}^{\text {Chamfer }}=\frac{\rho_{C \_D C-E B}}{A_{C \_D C-E B}^{\text {Chamfer }}}$

where $R_{C_{-} D C-E B}^{\text {Chamfer }}[\Omega]$ is the contact resistance between the DC and the EB layers for the chamfered samples and $A_{C_{-} D C-E B}^{\text {Chamfer }}\left[\mathrm{m}^{2}\right]$ 
is the contact surface between the DC and the EB layers for the chamfered samples.

\section{Results}

\section{A. Y-Axis Intercept, Contact Resistance, and Contact Resistivity}

$\mathrm{Y}$-axis intercept, contact resistance and contact resistivity results (average and standard deviation) are given in Table 2. The mean and standard deviation values were quantified by conducting the experiment on four samples per each bonding configuration.

Both the contact region between the DC and the EB layers and the contact region between the EB layers and the spar showed the same trend in terms of contact resistivity. In fact, the best contact was assured by ECF and BIAX materials, which presented contact resistivities from one to two orders of magnitude smaller than UD. In addition, the contact resistivity on the spar surfaces was larger than the contact resistivity on the DC surfaces for all the assessed materials. This indicates that a worse contact was obtained at the spar interfaces.

\section{B. Error Analysis}

The possible sources of random and systematic error of the developed procedure were identified in order to take suitable control measures and minimise them.

\section{1) Resistance Measurements: Random and Systematic Errors}

According to the manufacturer datasheet, the AIM TTi BS407 low resistance ohmmeter presents $0.1 \%$ accuracy [58], which contributed to the random error of the measurements. The instrument calibration was evaluated before starting the experiment by measuring three different shunt resistances, and the returned values were within $0.1 \%$ of the nominal ones.

Four samples per each bonding configuration were assessed to account for the manufacturing random error introduced by geometrical variations, variability in volume fraction of the constituent materials, etc. The sample-to-sample differences (standard deviations in Table 2) were up to $1 \%, 3 \%$, and $5 \%$ for UD, BIAX, and ECF configurations, respectively. On the other hand, multiple measurements on the same sample produced an uncertainty of less than $0.1 \%$. Since the manufacturing process was clearly the main source of random error, it was decided not to investigate the variation of measured resistance on the same sample.

Before conducting the experiment, it was important to consider the position of the measuring electrodes realized over the spar laminate. As the current is injected into the spar from its side, top, and bottom surfaces through the EB layers, it might initially remain confined in the outer layers because of the strong anisotropy of CFRP materials (see the current density streamlines in Fig. 9). In such conditions, the linear relationship between the total resistance and the length assumed in (1) and (5) would not be satisfied. To avoid this, it is necessary to place the measuring electrodes at a sufficient distance from the injection area (i.e., the EB region), in such a way that the current can spread through the entire spar thickness. The correct positions of the electrode were found by FEM simulations before the experiment. The ground boundary condition (i.e., the measuring electrode in the experimental setup) was adjusted over the spar surface and the variation of the total resistance as a function of the sample length was investigated. Fig. 9 shows, for the case of BIAX_DC-EB-SPAR_1, that the linearity between the total resistance and the length is lost when the distance between the EB layers and the ground position is smaller than $60 \mathrm{~mm}$. Consequently, it was decided to place the measuring electrodes in the last $100 \mathrm{~mm}$ of the spar where the current is uniformly distributed through the spar thickness and the linearity between total resistance and length satisfied.

To improve the ohmic contact with the carbon fibres and prevent incorrect readings, it was required to apply pressure over the measuring electrode surface. The systematic error due to surface roughness was reduced to around $1 \%$ when applying $20 \mathrm{MPa}$, as shown in Fig. 10.

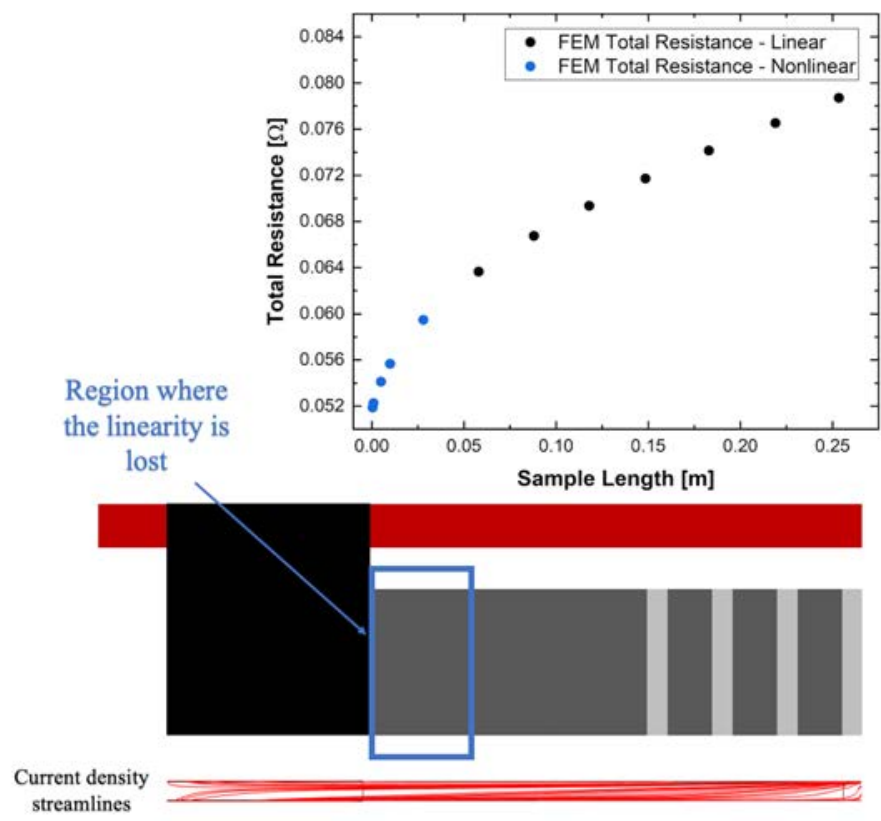

Fig. 9. Position of measuring electrode to satisfy the linear relationship between measured resistance and length, and current streamlines within the spar.

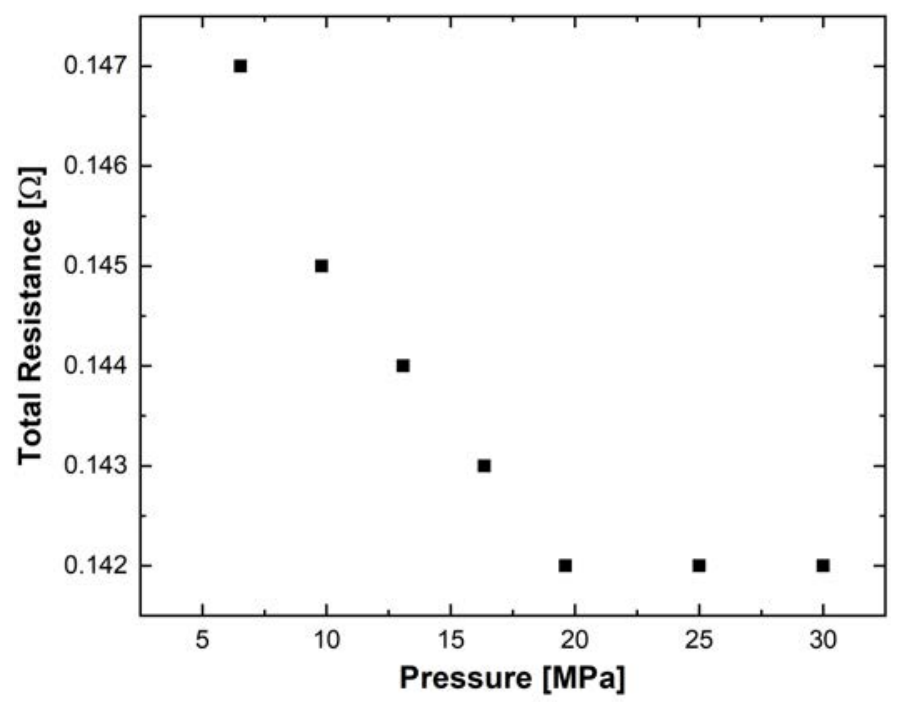

Fig. 10. Variation of total resistance as a function of pressure. 
Table 2. Y-axis intercept, contact resistance, and contact resistivity results.

\begin{tabular}{|c|c|c|c|c|c|c|c|c|c|c|c|c|c|c|c|}
\hline 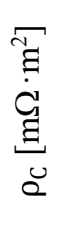 & $\begin{array}{l}\overrightarrow{8} \\
0 \\
0 \\
+1 \\
\infty \\
0 \\
0\end{array}$ & $\begin{array}{l}\overrightarrow{8} \\
0 \\
0 \\
+1 \\
\overrightarrow{0} \\
\dot{0}\end{array}$ & $\begin{array}{l}\overline{8} \\
8 \\
0 \\
0 \\
+1 \\
8 \\
8 \\
8 \\
0\end{array}$ & 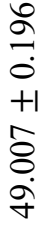 & 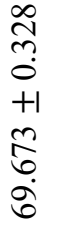 & 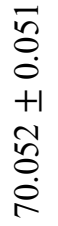 & 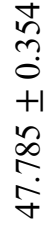 & $\begin{array}{l}\stackrel{1}{0} \\
0 \\
0 \\
+1 \\
+1 \\
\infty \\
0 \\
0\end{array}$ & 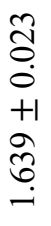 & 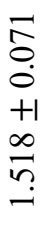 & 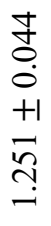 & 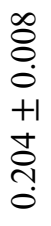 & $\begin{array}{l}n \\
0 \\
0 \\
+1 \\
n \\
\tilde{a} \\
\vdots \\
0\end{array}$ & \begin{tabular}{l}
$\stackrel{+}{0}$ \\
0 \\
0 \\
+1 \\
$n$ \\
\multirow{2}{*}{} \\
0 \\
0
\end{tabular} & $\begin{array}{l}\stackrel{\infty}{1} \\
0 \\
0 \\
+1 \\
\sim \\
\tilde{n} \\
\tilde{n}\end{array}$ \\
\hline 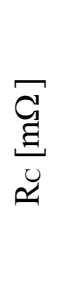 & 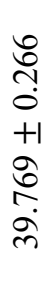 & 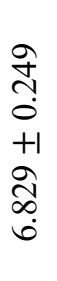 & $\begin{array}{l} \pm \\
\vdots \\
0 \\
+1 \\
+ \\
\infty \\
\infty \\
0\end{array}$ & 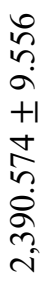 & 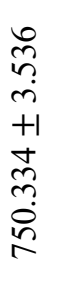 & 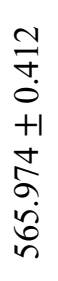 & 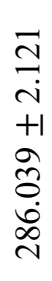 & $\begin{array}{l}0 \\
2 \\
n \\
+1 \\
+1 \\
2 \\
\infty \\
m \\
m\end{array}$ & 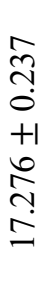 & 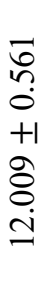 & 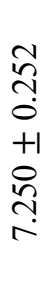 & $\begin{array}{l}\approx \\
\tilde{n} \\
0 \\
+1 \\
n \\
\dot{a} \\
a\end{array}$ & 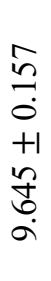 & $\begin{array}{l}n \\
\\
0 \\
+1 \\
\\
\end{array}$ & $\begin{array}{l}\overrightarrow{0} \\
\ddot{0} \\
+1 \\
+1 \\
0 \\
0 \\
\dot{0}\end{array}$ \\
\hline 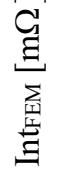 & 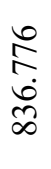 & $\begin{array}{l}\vec{N} \\
\infty \\
i\end{array}$ & $\begin{array}{l}\text { ఫे } \\
\text { ণे }\end{array}$ & $\begin{array}{l}\frac{0}{\infty} \\
\frac{1}{3} \\
\hat{\sigma}_{0}\end{array}$ & 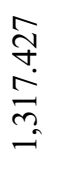 & 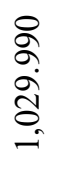 & 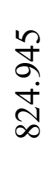 & $\begin{array}{l}\circ \\
\text { के } \\
\frac{1}{0}\end{array}$ & $\underset{\nabla}{\approx}$ & $\begin{array}{l}\stackrel{\Im}{\Im} \\
\stackrel{\sim}{\sim}\end{array}$ & 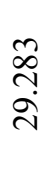 & $\frac{m}{\infty}$ & $\begin{array}{c}\stackrel{\overbrace{}}{\sim} \\
\stackrel{n}{n}\end{array}$ & $\begin{array}{l}\circ \\
\infty \\
\text { ம }\end{array}$ & $\begin{array}{l}\bar{\sigma} \\
\stackrel{n}{n}\end{array}$ \\
\hline 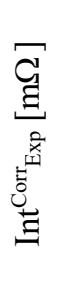 & 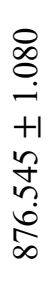 & 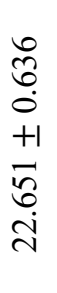 & 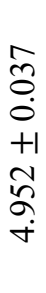 & 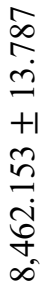 & 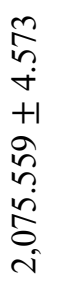 & 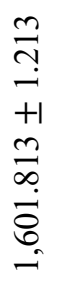 & 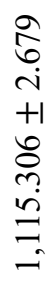 & \begin{tabular}{l}
\multirow{J}{\sigma}{} \\
$\dot{0}$ \\
+1 \\
$\dot{J}$ \\
$\stackrel{+}{\sigma}$ \\
$\dot{0}$
\end{tabular} & 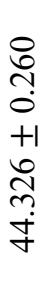 & 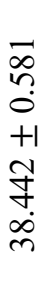 & 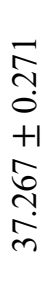 & $\begin{array}{l}\infty \\
\infty \\
0 \\
+1 \\
+1 \\
\hat{0} \\
\vdots \\
\dot{d}\end{array}$ & $\begin{array}{l}\mathbb{J} \\
\overrightarrow{0} \\
+1 \\
\hat{N} \\
i n \\
n\end{array}$ & 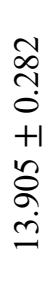 & $\begin{array}{l}0 \\
0 \\
0 \\
+1 \\
+1 \\
\tilde{n} \\
\infty \\
\infty\end{array}$ \\
\hline 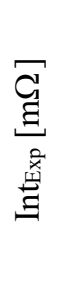 & $\begin{array}{l}\stackrel{8}{\infty} \\
\stackrel{0}{0} \\
\stackrel{-}{+} \\
+1 \\
2 \\
\infty \\
\infty \\
\infty \\
\infty \\
\infty\end{array}$ & 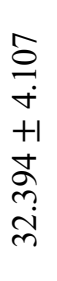 & \begin{tabular}{l}
$\hat{n}$ \\
0 \\
0 \\
+1 \\
\multirow{2}{n}{} \\
0 \\
$\dot{n}$
\end{tabular} & 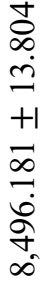 & 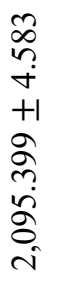 & 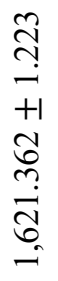 & 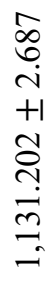 & 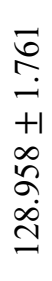 & $\begin{array}{l}n \\
n \\
0 \\
+1 \\
+1 \\
0 \\
0 \\
\infty \\
\infty\end{array}$ & 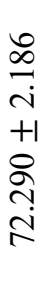 & 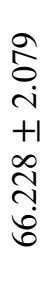 & 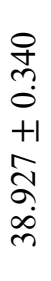 & $\begin{array}{l}\hat{n} \\
\stackrel{2}{+} \\
+1 \\
\dot{+} \\
\stackrel{+}{+} \\
\dot{+}\end{array}$ & 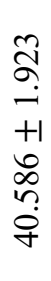 & 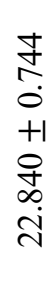 \\
\hline & & & & & 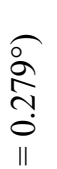 & 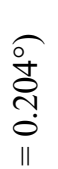 & 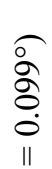 & & 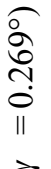 & $\frac{\overbrace{}}{\frac{\sigma}{\sigma}}$ & $\begin{array}{l}\stackrel{\bigcirc}{\hat{\sigma}} \\
\stackrel{\circ}{\circ} \\
\stackrel{0}{1}\end{array}$ & & 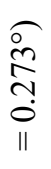 & 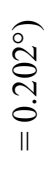 & 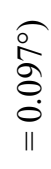 \\
\hline 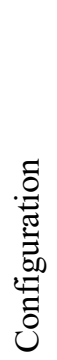 & 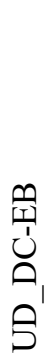 & 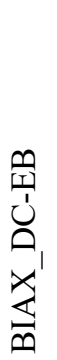 & 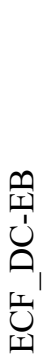 & 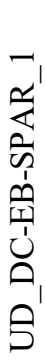 & 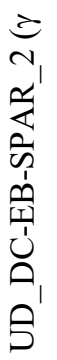 & 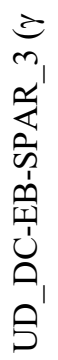 & 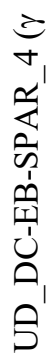 & 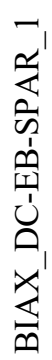 & 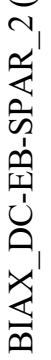 & 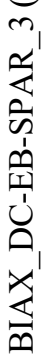 & 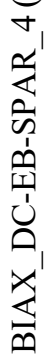 & 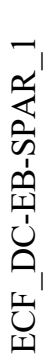 & 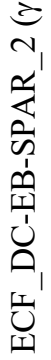 & 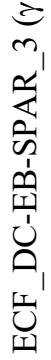 & 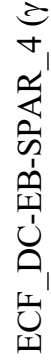 \\
\hline
\end{tabular}

The contact resistance of the measuring electrodes (that is, $\left.R_{C_{-} \text {Electrodes }}\right)$ needed to be deducted from the y-axis intercept to avoid inaccurate estimations of the sought interface resistances (i.e., $R_{C_{-} D C-E B}$ and $R_{C_{-} E B-S P A R}$ ). Highly conductive materials were utilised to reduce the resistance of the measuring electrodes: silver paint with a conductivity of $1 \times 10^{5} \mathrm{~S} / \mathrm{m}$; and copper tape with a conductivity equal to $5.998 \times 10^{7} \mathrm{~S} / \mathrm{m}$. Such materials have effectively been employed for CFRP resistance measurements in previous research [33], [34], [49], [59], [60]. Despite the employment of materials with high conductivity, the measuring electrode contact resistances were still significant, i.e., up to $60 \%$ of the $y$-axis intercept in the ECF configurations (see Table 2).

\section{2) Systematic Error Introduced by the Experimental- Numerical Approach}

The main systematic error source of the developed procedure (combination of experimental and numerical methods) was represented by the estimation of the spreading resistance around the contacts. In fact, the prediction of this resistance depends on the assumptions and modeling strategies implemented in the 
numerical simulations. First, the uncertainty was introduced when assuming ideal contact condition, which was used to calculate the combined resistance of DC, spar, and EB layers given in (9) and (10). Such a condition assumes that all the contact points at the interface regions do not experience any resistance, which affects the distribution of the current in the spar and thus the value of spreading resistance. Second, commercial FEM packages model electrical contacts as homogeneous surface conditions, that is, all the points of the interface are in contact and experience the same contact quality. This is not the case of real bonding interfaces as they do not experience contact at all points, nor with the same quality. In fact, there are areas of the interface where the conducting parts are in contact with each other and other areas where they are separated by the resin. The homogeneous contact condition influenced the way the current entered and distributed within the spar and thus the prediction of the spreading and spar resistances in the simulations.

The procedure uncertainty was quantified by comparing the experimental total resistances with the FEM ones computed with the contact resistances included in the model. According to the results given in Figs. 11-13, the observed discrepancies were more prominent for the ECF and UD samples, which were
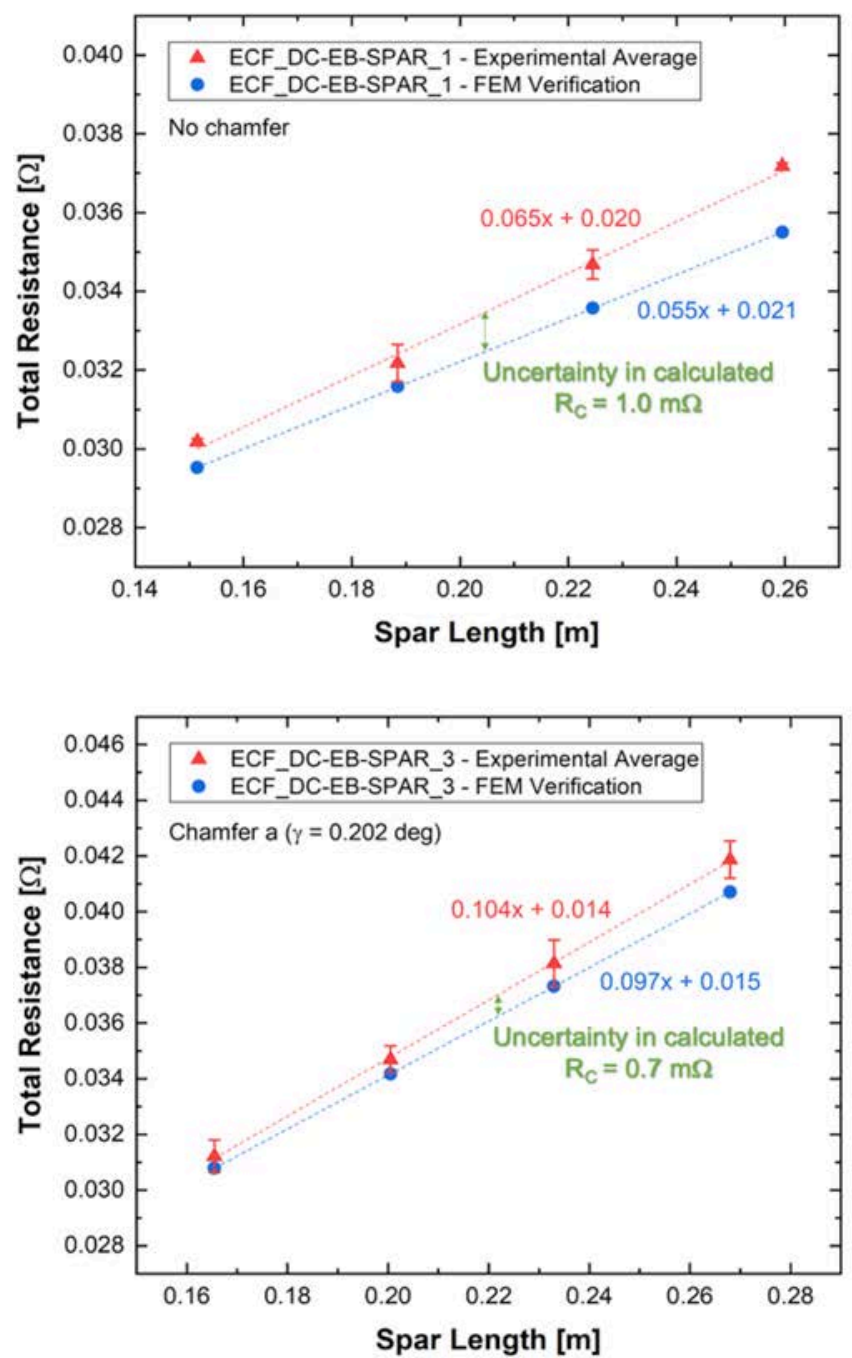

$\sim 10 \%$ of their calculated contact resistances. On the other hand, BIAX presented uncertainties close to $5 \%$ of its contact resistance. Experimental and FEM results also differed in the value of the spar resistance (i.e., the slope of the linear fitting) since the spar spreading resistance was affected by the modeling strategies of the numerical analysis, as outlined in the previous paragraph. When comparing ECF and BIAX configurations, it is noted that they were characterized by slightly different experimental slopes and thus by different spar resistances. The small difference between the experimental slopes of ECF and BIAX (i.e., the small increase in apparent spar resistance in ECF configurations) should be due to the inherent shape of the ECF sheets, which consists of several wires and diamond openings (see Fig. 6). The latter reduce the contact surface between the ECF and spar layers and increase the spreading resistance in the spar and thus the measured spar resistance. This conclusion is supported by the fact that the FEM slopes (i.e., the FEM spar resistances) of both ECF and BIAX were similar. The difference between the slopes of ECF and BIAX could not accurately be captured by the numerical simulations since the ECF layers were modelled as uniform sheets having anisotropic (effective) conductivity rather than
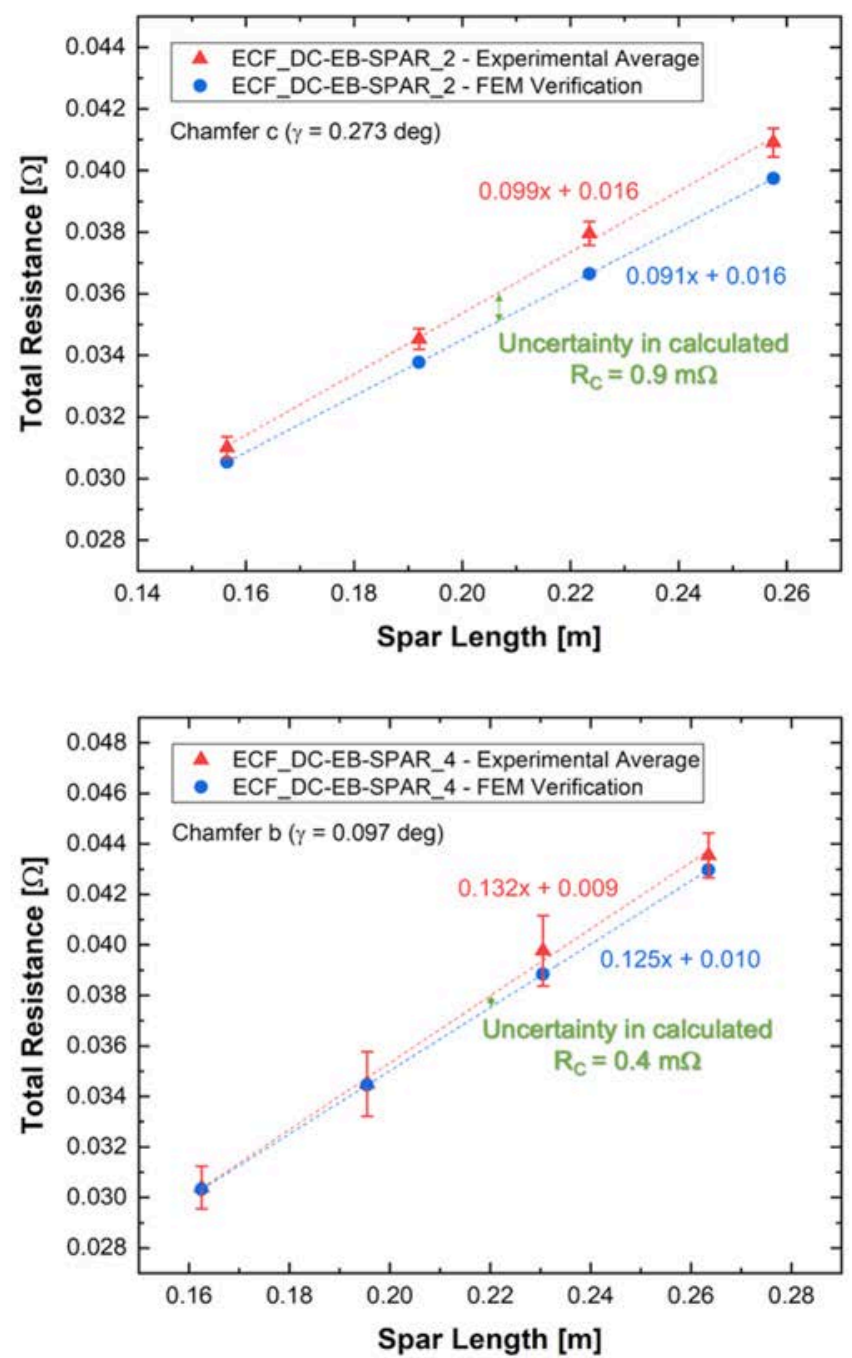

Fig. 11. ECF configurations: experimental and FEM total resistances. The error bars denote the standard deviation. 

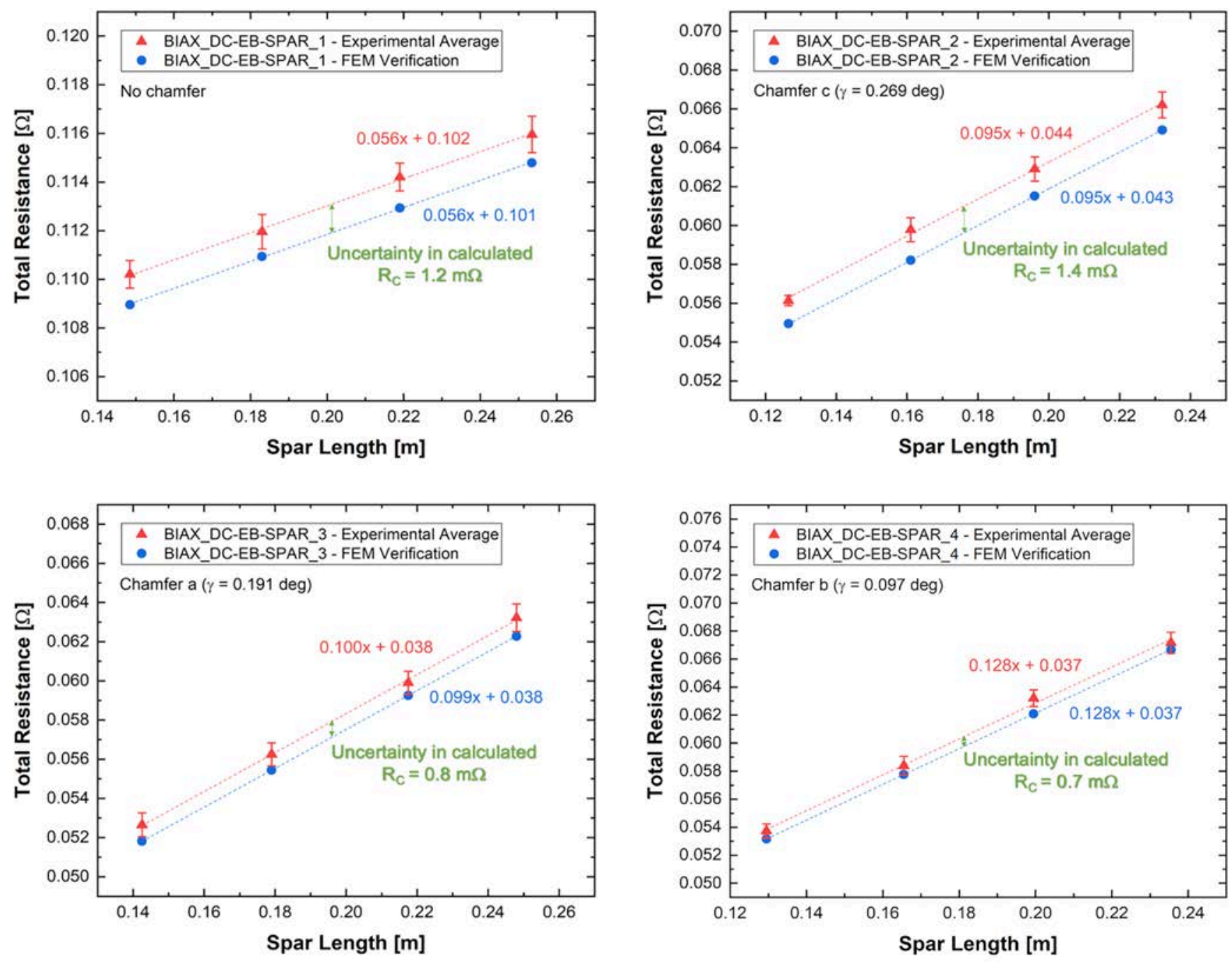

Fig. 12. BIAX configurations: experimental and FEM total resistances. The error bars denote the standard deviation.

the actual open-area structure. Higher accuracy would be obtained if the real ECF geometry was modelled, although it would be completely unpractical. For this reason and considering the low contact resistance provided by ECF material, it was decided to accept the $10 \%$ uncertainties in the calculated contact resistance. On the other hand, the slope of the UD configurations was nearly ten times larger than both ECF and BIAX slopes because of a highly non-uniform current density distribution in the spar. This was due to the low transverse conductivity of the UD material, which did not allow the current to spread on the entire contact surfaces with the spar. This increased the spar and total resistances of the UD EB samples by $\sim 1$ order of magnitude.

To conclude, the assumptions and modeling strategies adopted in the numerical simulations (i.e., the initial ideal contact condition and the homogeneous modeling of electrical contact) did not significantly affect the results since the uncertainties of the procedure were approximately one order of magnitude smaller than the contact resistance. Therefore, it is safe to assume that the presented methodology (combination of experimental and numerical techniques) is reliable and allows to characterize the electrical contact of wind turbine blade EB joints.

\section{Discussion}

Lower values of contact resistance are found on the chamfered surfaces for all the assessed EB materials. This is due to the fact that more contact points are obtained between the EB layers and the spar carbon fabrics. In fact, while in the nonchamfer samples (DC-EB-SPAR_1) the contact occurs on the side, top, and bottom surfaces of the spar only, in the chamfer specimens the contact is also established with the cross section of each spar layer. In addition, Fig. 14 shows that the smaller the chamfer angle is, the better the contact becomes (i.e., lower contact resistance), which might suggest that the number of contact points grows as the spar thickness varies gradually.

Final considerations are made on the assessed materials based on the electrical contact results (see Table 2). However, no definitive conclusion can be drawn on their performance as EB material without verifying their response under simulated lightning currents [12], [15]. ECF exhibits the lowest values of contact resistivity and thus the best contact behaviour compared to the other configurations. Although the contact resistivities provided by BIAX are $\sim 1$ order of magnitude higher than the 
ECF ones, it can still be considered a good candidate for EB applications thanks to the high in-plane conductivity. However,
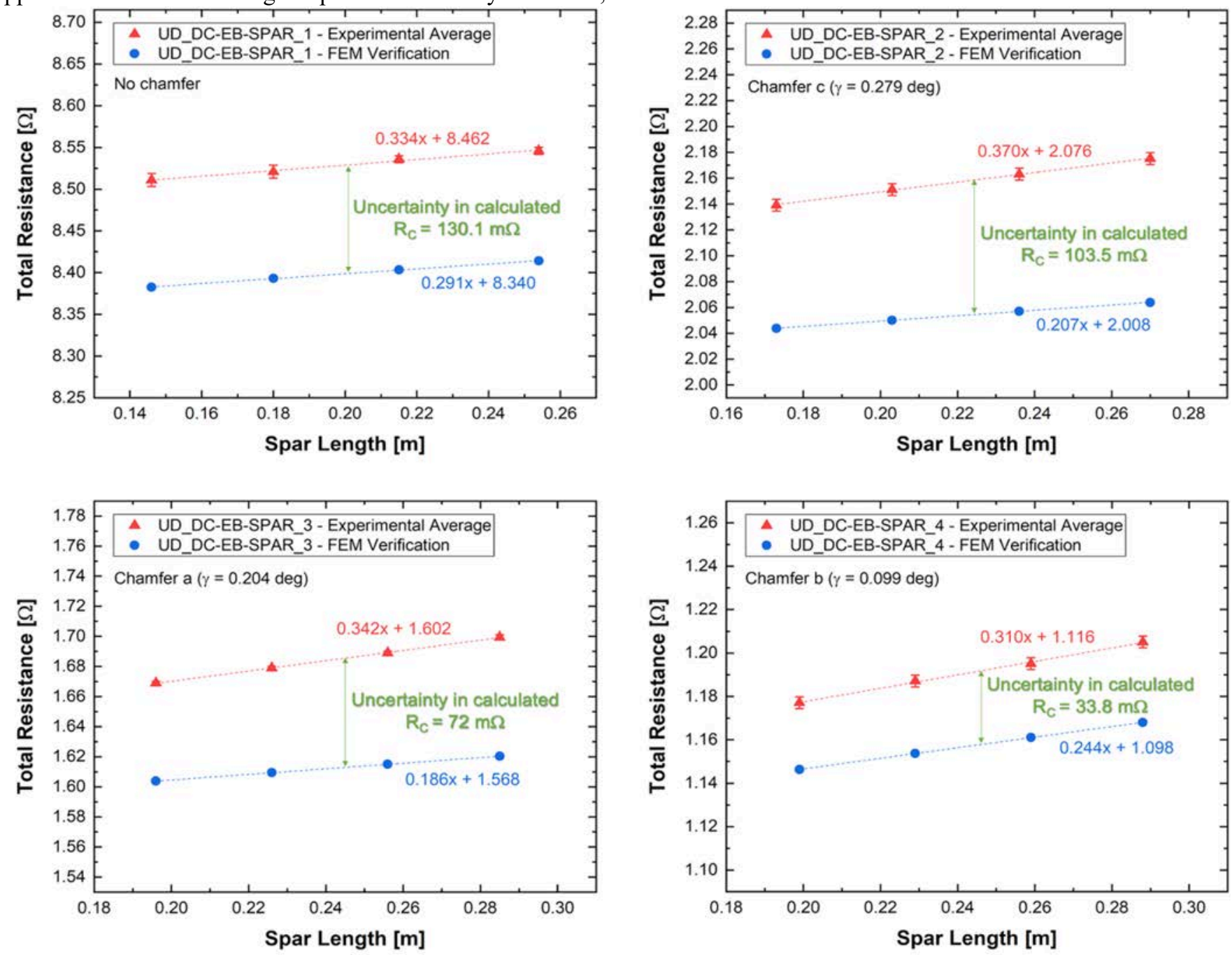

Fig. 13. UD configurations: experimental and FEM total resistances. The error bars denote the standard deviation.

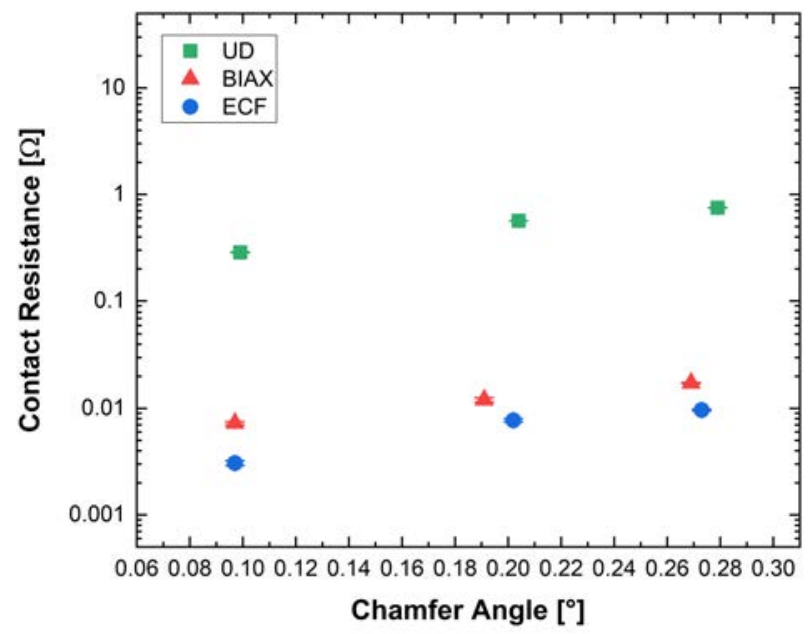

Fig. 14. Variation of $\mathrm{R}_{\mathrm{C} \_ \text {EB-SPAR }}$ as a function of the chamfer angle.

the same cannot be said for UD since it presents contact resistivities that are two orders of magnitude larger than the ECF contact resistivities. One reason for the superior contact behaviour provided by the ECF layers is the morphology of this material. In fact, the thick and stiff ECF strands exert a higher pressure over the spar carbon fibres during the vacuum infusion process, which squeezes the resin into the diamond openings. In this way, more contact points are obtained between the ECF wires and the spar carbon fibres, reducing the local contact resistance. Furthermore, the high electrical conductivity of this material (from three to seven orders of magnitude larger than CFRP conductivities) assures lower local resistances at the physical contact points [51], [61], [62]. On the other hand, carbon fibres are more flexible due to their small diameter ( 1$10 \mu \mathrm{m}$ [63]). As a consequence, most of the resin concentrates in between the EB and the spar layers (i.e., the contact interfaces) and forms resin-rich interlaminar regions. In addition, the formation of interlaminar resin areas is also favored by fibre volume fractions larger than $50 \%$ as carbon fibres are arranged in close proximity to one another and impede the resin to infiltrate in between them [49], [64], [65]. Hence, for the case of carbon fibre based EB layers, a higher concentration of resin at the contact areas leads to larger values of local resistance at the contact points. In the particular case of 
the UD material, the contact performance is further diminished by the low transverse conductivity of this material, which does not allow the current to spread over the entire interface surfaces, reducing the amount of local contact points. The limitation in conduction capability of CFRP materials caused by both the carbon fibres anisotropy and the presence of resin-reach interlaminar regions is a well-known issue. Recent research has proposed various methods of improving the electrical conductivity in CFRP [49], [66], [67]. For this particular case, the electrical contact behavior might be improved by the dispersion of conducting nanofillers within the epoxy matrix [68]-[71]. These particles would reduce the local resistance at the contact points, as well as they would enhance the transverse conductivity. The latter would in turn facilitate the spreading of the current on the spar contact surfaces in the case of UD EB.

Finally, past research shows that the contact resistivity of CFRPs decreases with increasing temperatures [39]-[41]. Furthermore, this change appears to be inversely proportional to the change in through-thickness conductivity of the bulk CFRP material. For instance, a drop in contact resistivity of $\sim 10 \%-20 \%$ from 20 to $150{ }^{\circ} \mathrm{C}$ roughly corresponds to an increase of $\sim 10 \%-20 \%$ in bulk through-thickness conductivity [36], [37], [39], [40]. On the other hand, this article considers the ambient temperature case in order to investigate the scenario with the highest contact resistivity. As a result, the Joule heating at the interface regions would be overestimated when the ambient temperature values are implemented in FEM models to predict the lightning current damage in the joint. Therefore, the use of ambient temperature contact resistivities in numerical simulations should mainly be limited to the identification of the damage onset and location, whereas no exact information can be provided on the extent of damage.

\section{CONCLUSION}

This article presents an alternative approach to estimate the electrical contact behaviour in complex joints such as equipotential connections used for wind turbine blades lightning protection. For such assemblies, the use of the standard two-probe method alone results to be unsuccessful because of the spreading effects in CFRP components and of the complicated geometrical arrangement (the samples are encapsulated within insulating GFRP layers representing the blade shell). In order to overcome them and determine the contact resistance, the developed procedure combines experimental measurements with FEM simulations.

The experiment was conducted at ambient temperature to assess the electrical contact in the worst case scenario, i.e., the case with the highest electrical contact resistivity. The procedure showed good accuracy when applied to three different EB materials, i.e., UD, BIAX, and ECF. The observed uncertainties between the experimental and numerical total resistances were within $10 \%$. These discrepancies were due to the assumptions and modeling strategies made in the FEM simulations, i.e., the initial ideal contact condition and the homogeneous electrical contact condition. Both ECF and BIAX assured better contacts than UD thanks to their high in-plane conductivity (larger than $10^{4} \mathrm{~S} / \mathrm{m}$ ). For all the assessed EB materials, the contact resistance was reduced on the chamfered surfaces and lower values of contact resistance were found as the chamfer angle was decreased. This trend indicated that more contact points were established between the EB layers and the chamfered layers of the spar.

The quality of the electrical contact might be improved through the dispersion of conducting nanofillers into the epoxy resin used for the bonding. The inclusion of these particles would enhance the conductivity of the epoxy, reducing the local resistance at the contact points.

Finally, it is known that the contact resistivity decreases with increasing temperatures. As a result, the implementation of ambient temperature values in FEM models to predict lightning current damage would lead to an overestimation of the Joule heating at the bonding interfaces. Thus, the use of ambient temperature contact resistivities should only be limited to estimate the damage onset and the approximate location in the joint.

\section{ACKNOWLEDGMENT}

The authors would like to thank N. Ohlerich and T. Theur from Nordex Energy GmbH for the technical support during the design and manufacturing of the samples assessed in this work. The authors would also like to acknowledge Dexmet Corporation for providing the expanded copper foil material.

\section{REFERENCES}

[1] K. Merker, "HALIADE-X Shaping the Future," Presented at the Wind Mission Lithuania 2020 International Conference, unpublished.

[2] O. T. Thomsen, "Sandwich materials for wind turbine blades - Present and future," J. Sandw. Struct. Mater., vol. 11, no. 1, pp. 7-26, 2009.

[3] P. Brøndsted and R. P. L. Nijssen, Advances in Wind Turbine Blade Design and Materials. Cambridge: Woodhead Publishing Limited, 2013.

[4] J. Zangenberg and P. Brøndsted, Fatigue life in textile composites used for wind energy engineering. Elsevier Ltd, 2015.

[5] L. Mishnaevsky, K. Branner, H. N. Petersen, J. Beauson, M. McGugan, and B. F. Sørensen, "Materials for wind turbine blades: An overview," Materials (Basel)., vol. 10, no. 11, pp. 1-24, 2017.

[6] F. Rachidi et al., "A Review of Current Issues in Lightning Protection of New-Generation Wind-Turbine Blades," IEEE Trans. Ind. Electron., vol. 55 , no. 6, pp. 2489-2496, 2008 .

[7] Y. Yasuda and S. Yokoyama, "Proposal of Lightning Damage Classification to Wind Turbine Blades," in 7th Asia-Pacific International Conference on Lightning, 2011, pp. 368-371.

[8] A. Candela Garolera, S. F. Madsen, M. Nissim, J. Myers, and J. Holboell, "Lightning Damage to Wind Turbine Blades From Wind Farms in U.S.," IEEE Trans. Power Deliv., vol. 31, no. 3, pp. 1-1, 2016.

[9] J. Montanyà, "Lightning interaction and damages to wind turbines," in $V$ Russian Conference on Lightning Protection, 2016, pp. 1-15.

[10] Q. Zhou, C. Liu, X. Bian, K. L. Lo, and D. Li, "Numerical analysis of lightning attachment to wind turbine blade," Renew. Energy, vol. 116, pp. 584-593, 2018.

[11] International Electrotechnical Commission, "IEC62305, Protection against lightning Part 1: General principles," Geneva, 2010.

[12] International Electrotechnical Commission, "IEC 61400 Ed. 2.0, Wind energy generation systems - Part 24: Lightning protection," Geneva, 2019.

[13] S. Haigh, "Recommended Practices for Wind Turbine Testing Lightning Protection for Wind Turbine Installations," 1997.

[14] A. Smorgonskiy, F. Rachidi, and M. Rubinstein, "Modeling lightning current distribution in conductive elements of a wind turbine blade," in International Conference on Lightning Protection, 2014, pp. 1415-1417.

[15] A. A. M. Laudani, I. O. Golosnoy, J. Kremer, E. C. Senis, O. T. Thomsen, and P. L. Lewin, "Experimental Characterisation of Contact Resistivity for CFRP Wind Turbine Spars Equipotential Bonding," in IEEE Holm 
Conference on Electrical Contacts, 2019, pp. 278-285.

[16] H. Mulazimoglu and L. Haylock, "Recent Developments in Techniques to Minimize Lightning Current Arcing Between Fasteners and Composite Structure," in International Conference on Lightning and Static Electricity, 2011, pp. 1-16.

[17] L. Chemartin et al., "Direct Effects of Lightning on Aircraft Structure : Analysis of the Thermal , Electrical and Mechanical Constraints," $J$. Aerosp. Lab, vol. 9, no. 5, pp. 1-15, 2012.

[18] L. Chemartin, P. Lalande., and F. Tristant, "Modeling and Simulation of Sparking in Fastenning Assemblies," in International Conference on Lightning and Static Electricity, 2013, pp. 1-7.

[19] S. Evans, I. Revel, M. Cole, and R. Mills, "Lightning strike protection of aircraft structural joints," in International Conference on Lightning Protection (ICLP), 2014, pp. 1952-1959.

[20] C. Karch and C. Metzner, "Lightning protection of carbon fibre reinforced plastics - An Overview," in 33rd International Conference on Lightning Protection, 2016, pp. 1-8.

[21] S. Evans et al., "An introduction to a new aerospace lightning direct effects research programme and the significance of zone $2 \mathrm{~A}$ waveform components on sparking joints," in 33rd International Conference on Lightning Protection, 2016, pp. 1-6.

[22] P. Monferran, C. Guiffaut, A. Reineix, F. Fustin, and F. Tristant, "Lightning Currents on Fastening Assemblies of an Aircraft Fuel Tank, Part I: Uncertainties Assessment With Statistical Approach," IEEE Trans. Electromagn. Compat., vol. 62, no. 3, pp. 807-817, 2020.

[23] P. Monferran, C. Guiffaut, A. Reineix, F. Fustin, and F. Tristant, "Lightning Currents on Fastening Assemblies of an Aircraft Fuel Tank, Part II: FDTD Modeling Merged with a Circuit Model Supplemented by a Statistical Model," IEEE Trans. Electromagn. Compat., vol. 62, no. 3, pp. 818-828, 2020.

[24] A. A. M. Laudani, I. O. Golosnoy, O. T. Thomsen, and P. L. Lewin, "Novel numerical models for the simulation of the electromagnetic response of CFRP wind turbine spars subjected to lightning strikes," in International Conference on Lightning and Static Electricity, 2019, pp. $1-9$.

[25] M. Zhang, Q. Li, H. Li, W. Yu, Z. Guo, and W. H. Siew, "Damage mechanism of wind turbine blade under the impact of lightning induced arcs," J. Renew. Sustain. Energy, vol. 11, no. 5, pp. 1-12, 2019.

[26] A. A. M. Laudani, I. O. Golosnoy, and O. T. Thomsen, "Numerical computation of lightning time-domain voltages using the Fourier analysis and the finite element method," in Tenth International Conference on Computational Electromagnetics, 2019, pp. 1-6.

[27] A. A. M. Laudani, L. Carloni, O. T. Thomsen, P. L. Lewin, and I. O. Golosnoy, "Efficient Method for the Computation of Lightning Current Distributions in Wind Turbine Blades using the Fourier Transform and the Finite Element Method," IET Sci. Meas. Technol., vol. 14, no. 7, pp. 786-799, 2020

[28] V. Mucsi et al., "Lightning protection methods for wind turbine blades: An alternative approach," Appl. Sci., vol. 10, no. 6, pp. 1-18, 2020.

[29] P. Monferran, C. Guiffaut, A. Reineix, F. Fustin, and F. Tristant, "Lightning Currents on Fastening Assemblies of an Aircraft Fuel TankPart III: Validation of the Current Assessment Method With Measurement," IEEE Trans. Electromagn. Compat., pp. 1-12, 2020.

[30] Dexmet Corporation, "Dexmet Expanding Materials," Wallingford, USA, 2017.

[31] Mueller Brass Co., "Alloy C11000 Electrolytic Tough Pitch Copper," 2018.

[32] F. Uhlig, "Contribution a l'etude des e ets directs du foudroiement sur les materi- aux structuraux constituant un aeronef (Contribution to the study of the lightning direct effects on the aircraft structural materials)," Université de Paris, PhD Thesis, 1998.

[33] R. D. Chippendale, "Modelling of the Thermal Chemical Damage Caused to Carbon Fibre Composites," University of Southampton, PhD Thesis, 2013.

[34] E. C. Senis, O. Vryonis, I. O. Golosnoy, O. T. Thomsen, J. M. DulieuBarton, and S. F. Madsen, "Reducing the electrical anisotropy in unidirectional CFRP materials for wind turbine blade applications," in International Conference on Lightning and Static Electricity, 2017, pp. $1-5$.

[35] RS Components, "RS Pro Bottle of Silver Conductive Adhesive Paint (Stock No: 186-3600)," 2018.

[36] I. El Sawi, P. A. Olivier, P. Demont, and H. Bougherara, "Processing and electrical characterization of a unidirectional CFRP composite filled with double walled carbon nanotubes," Compos. Sci. Technol., vol. 73, no. 1, pp. 19-26, 2012.
[37] H. Yu, "Modelling and characterisation of electrical resistivity of carbon composite laminates," University of Delaware, PhD Thesis, 2018.

[38] J. B. Khan, A. C. Smith, P. M. Tuohy, M. Gresil, C. Soutis, and A. Lambourne, "Experimental electrical characterisation of carbon fibre composites for use in future aircraft applications," IET Sci. Meas. Technol., vol. 13, no. 8, pp. 1131-1138, 2019.

[39] S. Wang and D. D. L. Chung, "Electrical behavior of carbon fiber polymer-matrix composites in the through-thickness direction," J. Mater. Sci., vol. 35, no. 1, pp. 91-100, 2000.

[40] S. Wang, D. P. Kowalik, and D. D. L. Chung, "Self-sensing attained in carbon-fiber-polymer-matrix structural composites by using the interlaminar interface as a sensor," Smart Mater. Struct., vol. 13, no. 3, pp. 570-592, 2004.

[41] Q. Zhao et al., "Review on the electrical resistance/conductivity of carbon fiber reinforced polymer," Appl. Sci., vol. 9, no. 11, 2019.

[42] R. Holm, Electrical Contacts - Theory and Applications. Berlin: Springer-Verlag, 1967.

[43] P. Zhang, Y. Y. Lau, and R. S. Timsit, "On the spreading resistance of thin-film contacts," IEEE Trans. Electron Devices, vol. 59, no. 7, pp. 1936-1940, 2012.

[44] G. Norberg, S. Dejanovic, and H. Hesselbom, "Contact resistance of thin metal film contacts," IEEE Trans. Components Packag. Technol., vol. 29, no. 2, pp. 371-378, 2006.

[45] S. Karmalkar, P. V. Mohan, H. P. Nair, and R. Yeluri, "Compact models of spreading resistances for electrical/thermal design of devices and ICs," IEEE Trans. Electron Devices, vol. 54, no. 7, pp. 1734-1743, 2007.

[46] W. Ren, Y. Chen, Z. Wang, S. Xue, and X. Zhang, "Electrical Contact Resistance of Coated Spherical Contacts," IEEE Trans. Electron Devices, vol. 63, no. 11, pp. 4373-4379, 2016.

[47] Comsol 5.6, "AC / DC Module User 's Guide," 2020.

[48] Comsol 5.6, "Comsol Multiphysics Reference Manual," 2020.

[49] E. C. Senis, I. O. Golosnoy, J. M. Dulieu-Barton, and O. T. Thomsen, "Enhancement of the electrical and thermal properties of unidirectional carbon fibre/epoxy laminates through the addition of graphene oxide," $J$. Mater. Sci., vol. 54, no. 12, pp. 8955-8970, 2019.

[50] T. M. Dhanya and C. S. Yerramalli, "Lightning strike effect on carbon fiber reinforced composites - effect of copper mesh protection," Mater. Today Commun., vol. 16, pp. 124-134, 2018.

[51] Y. Guo, Y. Xu, Q. Wang, Q. Dong, X. Yi, and Y. Jia, "Enhanced lightning strike protection of carbon fiber composites using expanded foils with anisotropic electrical conductivity," Compos. Part A Appl. Sci. Manuf., vol. 117, pp. 211-218, 2019.

[52] H. H. Berger, "Contact Resistance and Contact Resistivity," $J$. Electrochem. Soc., vol. 119, no. 4, pp. 507-514, 1972.

[53] R. Hahn and M. E. Johansson, "New contact design for the ex situ fabrication of small size, low resistivity normal metal contacts to epitaxial c-axis YBCO films," IEEE Trans. Components Packag. Manuf. Technol. Part A, vol. 19, no. 1, pp. 105-112, 1996.

[54] D. K. Schroder, Semiconductor Material and device, 3rd Ed. Hoboken: John Wiley and Sons, 2006.

[55] S. Sze and K. K. Ng, Physics of Semiconductor Devices, 3rd Ed. John Wiley and Sons, 2007.

[56] N. Stavitski, "Silicide-to-silicon specific contact resistance characterization - test structures and models," University of Twente, PhD Thesis, 2009.

[57] B. J. Lwo, C. L. Teng, K. F. Tseng, T. Ni, and S. Lu, "Contact Resistance of Microbumps in a Typical Through-Silicon-Via Structure," IEEE Trans. Components, Packag. Manuf. Technol., vol. 7, no. 1, pp. 27-32, 2017.

[58] Aim TTi, "BS407 wide range precision micro-ohmeter," 2018.

[59] R. Abid, "Electrical Characterisation of Aerospace Grade Carbon-FibreReinforced Polymers," Cardiff University, PhD Thesis, 2015.

[60] J. Cheng, H. Ji, J. Qiu, T. Takagi, T. Uchimoto, and N. Hu, "Novel electromagnetic modeling approach of carbon fiber-reinforced polymer laminate for calculation of eddy currents and eddy current testing signals," J. Compos. Mater., vol. 49, no. 5, pp. 617-631, 2015.

[61] H. Kawakami and P. Feraboli, "Lightning strike damage resistance and tolerance of scarf-repaired mesh-protected carbon fiber composites," Compos. Part A Appl. Sci. Manuf., vol. 42, no. 9, pp. 1247-1262, 2011.

[62] M. Gagné and D. Therriault, "Lightning strike protection of composites," Prog. Aerosp. Sci., vol. 64, pp. 1-16, 2014.

[63] B. A. Newcomb, "Processing, structure, and properties of carbon fibers," Compos. Part A Appl. Sci. Manuf., vol. 91, pp. 262-282, 2016.

[64] K. Schulte and C. Baron, "Load and failure analyses of CFRP laminates by means of electrical resistivity measurements," Compos. Sci. Technol., 
vol. 36 , no. 1 , pp. $63-76,1989$.

[65] A. Todoroki, M. Tanaka, and Y. Shimamura, "Measurement of orthotropic electric conductance of CFRP laminates and analysis of the effect on delamination monitoring with an electric resistance change method," Compos. Sci. Technol., vol. 62, no. 5, pp. 619-628, 2002.

[66] E. C. Senis, I. O. Golosnoy, T. Andritsch, J. M. Dulieu-Barton, and O. T. Thomsen, "The influence of graphene oxide filler on the electrical and thermal properties of unidirectional carbon fiber/epoxy laminates: Effect of out-of-plane alignment of the graphene oxide nanoparticles," Polym. Compos., no. November 2019, pp. 1-11, 2020.

[67] S. C. Brown, C. Robert, V. Koutsos, and D. Ray, "Methods of modifying through-thickness electrical conductivity of CFRP for use in structural health monitoring, and its effect on mechanical properties - A review," Compos. Part A Appl. Sci. Manuf., vol. 133, p. 105885, 2020.

[68] O. Vryonis, T. Andritsch, A. S. Vaughan, and P. L. Lewin, "An alternative synthesis route to graphene oxide: influence of surface chemistry on charge transport in epoxy-based composites," J. Mater. Sci., vol. 54, no. 11, pp. 8302-8318, 2019.

[69] O. Vryonis, S. T. H. Virtanen, T. Andritsch, A. S. Vaughan, and P. L. Lewin, "Understanding the cross-linking reactions in highly oxidized graphene/epoxy nanocomposite systems," J. Mater. Sci., vol. 54, no. 4, pp. 3035-3051, 2019.

[70] O. Vryonis, T. Andritsch, A. S. Vaughan, and P. L. Lewin, "Structural and chemical comparison between moderately oxygenated and edge oxygenated graphene: mechanical, electrical and thermal performance of the epoxy nanocomposites," SN Appl. Sci., vol. 1, no. 10, pp. 1-10, 2019.

[71] O. Vryonis, T. Andritsch, A. S. Vaughan, and P. L. Lewin, "Effect of surfactant molecular structure on the electrical and thermal performance of epoxy/functionalized-graphene nanocomposites," Polym. Compos., no. March, pp. 1-15, 2020.

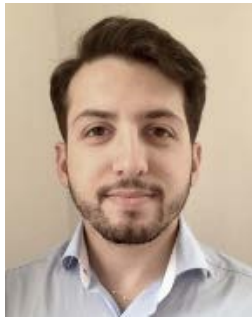

Antonio A.M. Laudani was born in Catania, Italy, in 1992. He received the B.Sc. degree in mechanical engineering from Politecnico di Torino, Italy, in 2015, and the M.Sc. degree in advanced mechanical engineering from the University of Sheffield, U.K., in 2016. He is currently working towards the Ph.D. degree in electronic and electrical engineering with the University of Southampton, U.K.

His research interests include numerical modeling of coupled electrical, thermal and mechanical phenomena, damage prediction in composite materials and lightning protection of wind turbine blades.

Mr. Laudani is a Marie Sklodowska-Curie Fellow.

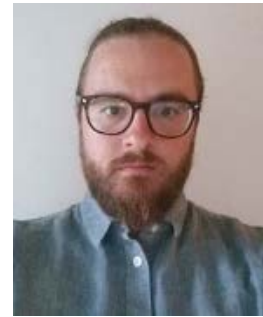

Evangelos C. Senis was born in Greece in 1990. He received the B.Sc. degree in materials science and the M.Sc. degree in polymer science and technology from the University of Patras, Patras, Greece, in 2014 and 2015, respectively, and the Ph.D. degree in composites engineering from the University of Southampton, Southampton, U.K., in 2020

His research interests include the development of nanocomposites and nanomodified fibre-reinforced polymer composites with improved electrical, thermal, and mechanical behaviour.

Dr. Senis is a Marie Sklodowska-Curie Fellow.

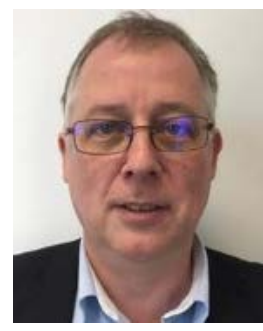

Paul L. Lewin (Fellow, IEEE) was born in Ilford, U.K., in 1964. He received the B.Sc. (Hons) and Ph.D. degrees in electrical engineering from the University of Southampton, Southampton, U.K., in 1986 and 1994, respectively.

In 1989, he joined the academic staff of the University of Southampton, where he is the Head of Electronics and Computer Science, and is also the Director of the Tony Davies High Voltage Laboratory. His research interests are within the generic areas of applied signal processing and control. Within high voltage engineering, this includes condition monitoring of $\mathrm{HV}$ cables and plant, surface charge measurement, HV insulation/dielectric materials, and applied signal processing. Since 1996, he has received funding and grants in excess of $£ 30 \mathrm{M}$, supervised 50 graduate students to successful completion of their doctoral theses and authored/co-authored more than 500 refereed conference and journal papers in these research areas.
Prof. Lewin is a Chartered Engineer, a Fellow of the IET, and Former President of the IEEE Dielectrics and Electrical Insulation Society.

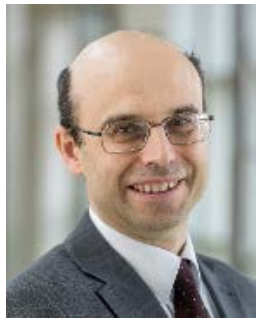

Igor O. Golosnoy received the M.Sc. degree in applied mathematics and physics from the Moscow Institute of Physics and Technology, Moscow, Russia, in 1992, and the Ph.D. degree in mathematics and physics from the Institute for Mathematical Modeling, Moscow, Russia, in 1995.

$\mathrm{He}$ is currently an Associate Professor with the Electrical Power Engineering Research Group, Faculty of Engineering and Physical Sciences, University of Southampton, Southampton, U.K. He has more than 25 years' experience in plasma physics, emission spectroscopy and plasma diagnostics, plasma material treatment, heat transfer and gas flow modeling. His research focuses on numerical modeling of physical processes in plasma involving breakdown and ionization phenomena with emphasis on gas discharge physics and optical emission spectroscopy of plasmas. He has authored more than 100 papers.

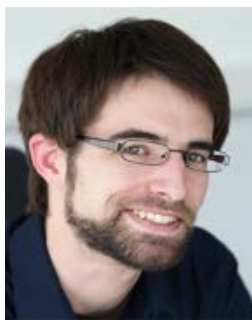

Jochen Kremer was born in Germany in 1985. He received the Diploma (Dipl.-Ing.) in electrical engineering and information technologies from the Karlsruhe Institute of Technology, Karlsruhe, Germany, in 2011.

Since 2011, he has been with Nordex Energy GmbH, Hamburg, Germany, in various positions, currently as an Expert Engineer with responsibility for lightning protection and electromagnetic compatibility. His research interests include high voltages, high currents, and lightning protection of rotor blades.

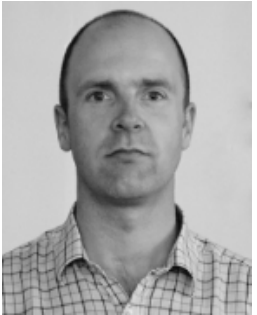

Hendrik Klein was born in Malchin, Germany, in 1976. He received the M.S. degree in mechanical engineering and shipbuilding in 2002, and the Ph.D degree from the University of Rostock, Rostock, Germany, in 2009.

From 2003 to 2008 he was a Research Assistant and Lecturer with the University of Rostock in the field of parametric modeling of medical scan data. In 2008, he joined Nordex Energy GmbH, Rostock, Germany, where he is the Head of the Rotor Blade Materials, Design and Tests Department. He is the author of two books, more than 20 articles, and more than 20 inventions. He has received numerous research grants throughout the last 15 years of work. His scientific focus is on the broad field of composites.

Dr. Klein is a Member of VDMA "Working Group Wind Industry".

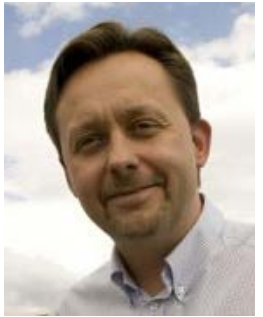

Ole T. Thomsen is the NCC Chair of Composites Design and Manufacturing, with the Bristol Composites Institute, and Department of Aerospace Engineering, University of Bristol, as well as the National Composites Institute (NCC), Bristol, UK. His prestigious appointments include: Chairman of Technology/Production Research Council of the Independent Research Fund Denmark (IRFD) 2012-2014 [ UU Engineering and Physical Sciences Research Council (EPSRC)]; Fellow of Danish Academy of Technical Sciences ( FREng in the U.K.) 2007; and Knighthood of Her Royal Majesty Queen Margrethe II of Denmark, 2012. He authored more than 110 papers in scientific journals, and more than 180 in proceedings from international conferences/workshops ( $\mathrm{h}=35$, Google Scholar). Principal Investigator (PI): numerous research grants through IRFD and 'Innovation Fund Denmark' (IFD) (grant income $\sim 15.1 \mathrm{M}$ ), EU H2020 and European Space Agency (grant income $\sim £ 6.1 \mathrm{M})$, and most recently EPSRC (£6.9M). Recent grants as PI: 'Blade King' 2009-2014 (IFD £7.7M), 'SPARCARB' 2016-2019 (H2020-MSCA-ITN2014, Grant 642771, £1.1M) and the EPSRC Programme Grant "CerTest" 20192024 (EP/S017038/1, £6.9M). In addition, Deputy Director of EPSRC Future Composites Manufacturing Hub, 2017-2023 (EP/P006701, £10.3M).

Prof. Thomsen chaired the ICCM20, Copenhagen 2015, with 2000 participants the largest conference ever on composites. 